\title{
Review
}

\section{The Emerging Role of Ionic Liquid-Based Approaches for Enhanced Skin Permeation of Bioactive Molecules: A Snapshot of the Past Couple of Years}

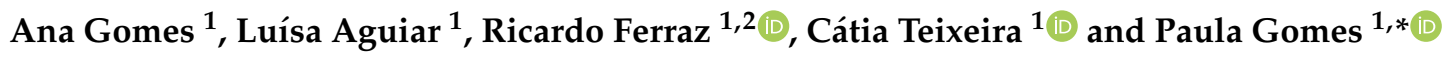 \\ 1 LAQV-REQUIMTE, Departamento de Química e Bioquímica, Faculdade de Ciências, Universidade do Porto, \\ Rua do Campo Alegre 687, P-4169-007 Porto, Portugal; anagomes@fc.up.pt (A.G.); luisa.silva@fc.up.pt (L.A.); \\ ricardoferraz@eu.ipp.pt (R.F.); catia.teixeira@fc.up.pt (C.T.) \\ 2 Ciências Químicas e das Biomoléculas, CISA, Escola Superior de Saúde, Politécnico do Porto, R. Dr. António \\ Bernardino de Almeida 400, P-4200-072 Porto, Portugal \\ * Correspondence: pgomes@fc.up.pt
}

Citation: Gomes, A.; Aguiar, L.; Ferraz, R.; Teixeira, C.; Gomes, P. The Emerging Role of Ionic Liquid-Based Approaches for Enhanced Skin Permeation of Bioactive Molecules: A Snapshot of the Past Couple of Years. Int. J. Mol. Sci. 2021, 22, 11991.

https://doi.org/10.3390/ijms222111991

Academic Editor: Anna Maria Piras

Received: 15 October 2021

Accepted: 3 November 2021

Published: 5 November 2021

Publisher's Note: MDPI stays neutral with regard to jurisdictional claims in published maps and institutional affiliations.

Copyright: (c) 2021 by the authors. Licensee MDPI, Basel, Switzerland. This article is an open access article distributed under the terms and conditions of the Creative Commons Attribution (CC BY) license (https:/ / creativecommons.org/licenses/by/ $4.0 /)$.

\begin{abstract}
Topical and transdermal delivery systems are of undeniable significance and ubiquity in healthcare, to facilitate the delivery of active pharmaceutical ingredients, respectively, onto or across the skin to enter systemic circulation. From ancient ointments and potions to modern micro/nanotechnological devices, a variety of approaches has been explored over the ages to improve the skin permeation of diverse medicines and cosmetics. Amongst the latest investigational dermal permeation enhancers, ionic liquids have been gaining momentum, and recent years have been prolific in this regard. As such, this review offers an outline of current methods for enhancing percutaneous permeation, highlighting selected reports where ionic liquid-based approaches have been investigated for this purpose. Future perspectives on use of ionic liquids for topical delivery of bioactive peptides are also presented.
\end{abstract}

Keywords: active pharmaceutical ingredients; complicated skin and soft tissue infections; cosmetics; ionic liquids; peptides; transdermal delivery; wound-healing

\section{Introduction}

The skin is the largest organ of the human body, protecting it against external aggressions while keeping its thermal regulation and conveying the sense of touch. Being such a formidable barrier, the skin may also be a considerable obstacle for efficient topical absorption and/or transdermal delivery of many active pharmaceutical ingredients (APIs) and cosmetics. Different strategies have been developed and explored over time to promote dermal permeation of different substances, since empirical formulations developed over five thousand years ago in the ancient Egyptian and Babylonian civilizations, to cutting-edge physical, chemical, and [bio]nanotechnological approaches that build on current knowledge of skin physiology, composition, and permeation routes (Figure 1) [1-3].

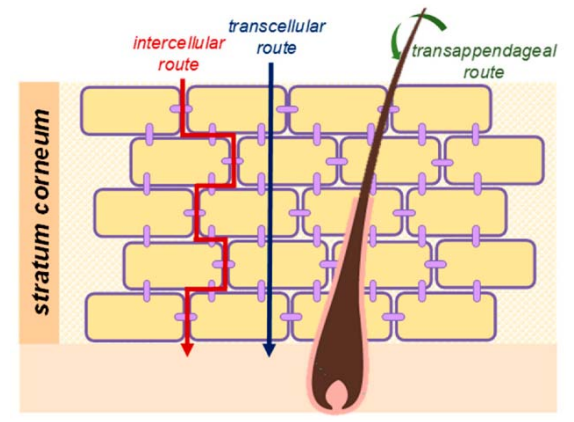

Figure 1. Schematic view of skin permeation pathways: intercellular, transcellular, and transappendageal [4]. Reprinted with permission from ref. [4]. Copyright 2021 MDPI. 
The evolution of strategies to promote percutaneous penetration of molecules and macromolecules is schematized in Figure 2 [5]. Current approaches encompass: (i) physical methods like sonophoresis, iontophoresis, thermophoresis, electroporation, laser microporation, thermal ablation, or microneedle patches [6]; (ii) encapsulation in suitable nanocarriers (nanoparticles, liposomes, ethosomes, niosomes, aquasomes, etc.) [7]; (iii) use of engineered controlled-release and/or stimuli-responsive materials (patches, wearable devices, and others) [8]; and (iv) addition of [bio]chemical permeation enhancers (e.g., fatty acids, fatty alcohols, alcohols, glycols, peptides, [bio]surfactants) [9]. Some of these methods can be combined, to further improve the percutaneous permeation efficiency.

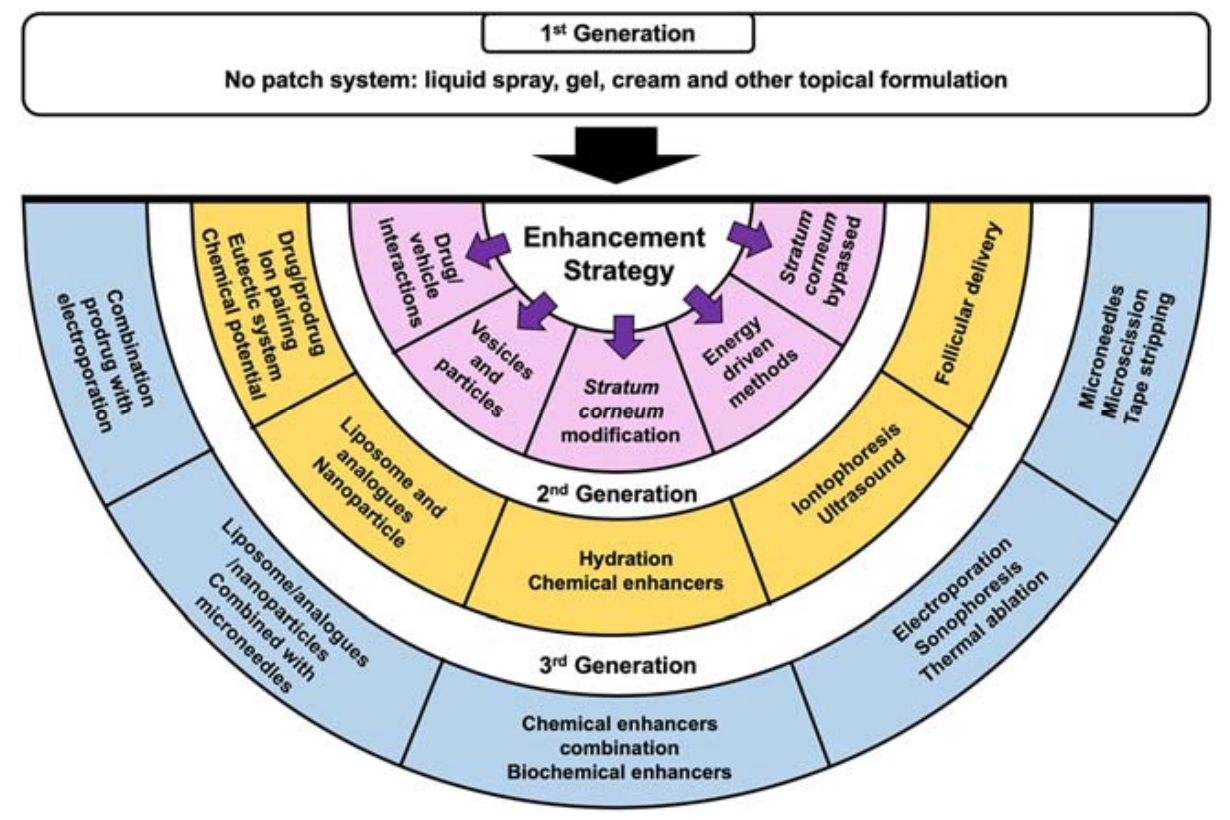

Figure 2. Diagram on the progress in the development of percutaneous absorption enhancement strategies [5]. Reprinted with permission from ref. [5]. Copyright 2021 Springer Nature.

Chemical permeation enhancers (CPEs) act through interactions with molecules that compose the stratum corneum (SC), the outermost layer of the skin that limits the rate of dermal/transdermal permeation. CPEs include different chemical families, such as alcohols (e.g., isopropyl alcohol), glycols (e.g., propylene glycol), terpenes and terpenoids (e.g., menthol), essential oils (e.g., eucalyptus), sulfoxides (e.g., dimethylsulfoxide), ether alcohols (Transcutol ${ }^{\circledR}$ ), and amides $\left(\right.$ Azone $^{\circledR}$ ), among many others [9]. The over 600 CPEs reported to date act via different pathways, the most common of which is disturbance of the cell membrane phospholipid bilayers [10]. As such, it comes with no surprise that an important portion of CPEs regard amphiphilic molecules such as fatty acids and respective esters, fatty alcohols, and several other anionic, cationic, zwitterionic, and non-ionic surfactants (Table 1) [9].

Table 1. Examples of amphiphilic chemical permeation enhancers (CPEs).

\begin{tabular}{|c|c|c|}
\hline \multirow{2}{*}{ Class } & \multicolumn{2}{|c|}{ Examples } \\
\hline & Name & Structure \\
\hline \multirow{3}{*}{ Fatty acids } & Lauric acid & $\mathrm{CH}_{3}\left(\mathrm{CH}_{2}\right)_{10} \mathrm{COOH}$ \\
\hline & Oleic acid & cis- $\mathrm{CH}_{3}\left(\mathrm{CH}_{2}\right)_{7} \mathrm{CH}=\mathrm{CH}\left(\mathrm{CH}_{2}\right)_{7} \mathrm{COOH}$ \\
\hline & Linoleic acid & $\stackrel{\text { cis,cis- }}{\mathrm{CH}_{3}\left(\mathrm{CH}_{2}\right)_{4} \mathrm{CH}=\mathrm{CHCH}{ }_{2} \mathrm{CH}=\mathrm{CH}\left(\mathrm{CH}_{2}\right)_{7} \mathrm{COOH}}$ \\
\hline
\end{tabular}


Table 1. Cont.

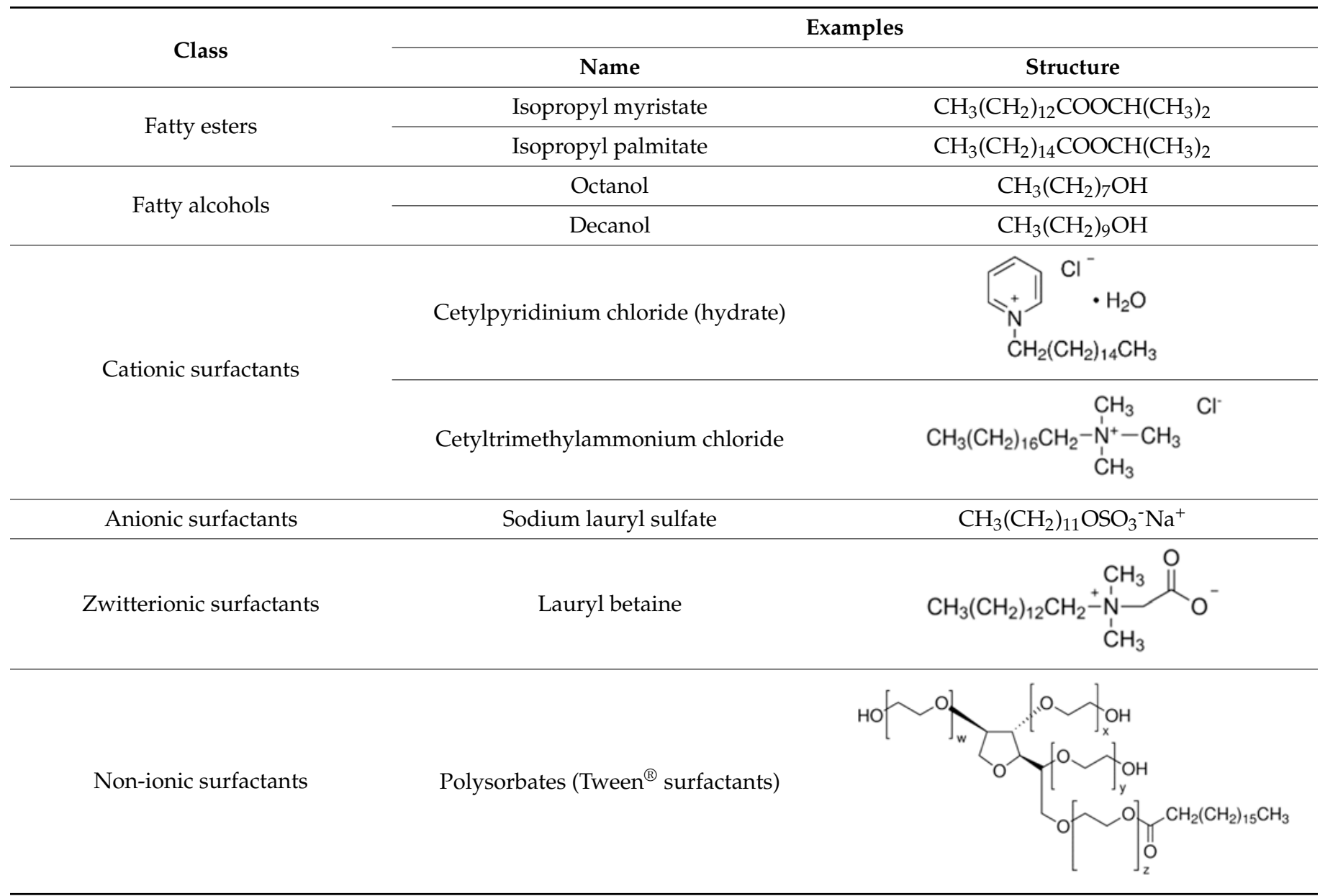

Cetylpyridinium chloride (Table 1) is one of the amphiphilic CPEs most commonly used in cosmetics, where it also acts as a preservative and antiseptic, due to its antimicrobial properties [11]. Cetylpyridinium chloride, by being an ionic pair that combines an organic cation (cetylpyridinium) with an inorganic (could be organic) anion, has the structural type of an ionic liquid. Ionic liquids (ILs) are generally defined as organic salts composed by an organic cation and an organic or inorganic anion that are stable below their melting point. ILs are known by their remarkable physical and chemical properties and by their possible customization, since they can be designed to exert the desired effect by the correct choice of the ions that compose them [12].

The relevance of ILs is currently consolidated in many areas that explore them as (i) greener alternatives to common organic solvents, (ii) task-specific materials, and (iii) polyvalent players in pharmaceutical sciences. In the latter field, a wide range of ILs have been developed, spanning from ILs with intrinsic bioactivity to those having suitable properties for drug formulation and transport $[13,14]$. In this regard, ILs have been advanced as high value mediators of dermal and transdermal delivery (DTD) of small and large molecules, whose properties can be tailored through a few simple design principles as recently proposed by Mitragotri and co-workers [15].

In view of the above, this review offers a snapshot of the latest developments regarding the most common methods for DTD of [bio]pharmaceuticals, highlighting the emerging role of ILs for enhancement of percutaneous absorption of diverse payloads, including proteins and peptides. 


\section{Overview of Current Methods for Dermal and Transdermal Drug Delivery}

\subsection{Physical Methods}

Physical methods to enhance percutaneous permeation can be divided into indirect and direct approaches (Figure 3). In indirect methods, different types of energy are used to promote penetration and diffusion of bioactive solutes through the SC. Thus, electrical energy is applied in electroporation and iontophoresis procedures, acoustic energy is used in sonophoretic methods (e.g., cavitation, ultrasound pressure), and laser or magnetic energies can also be applied in this context.

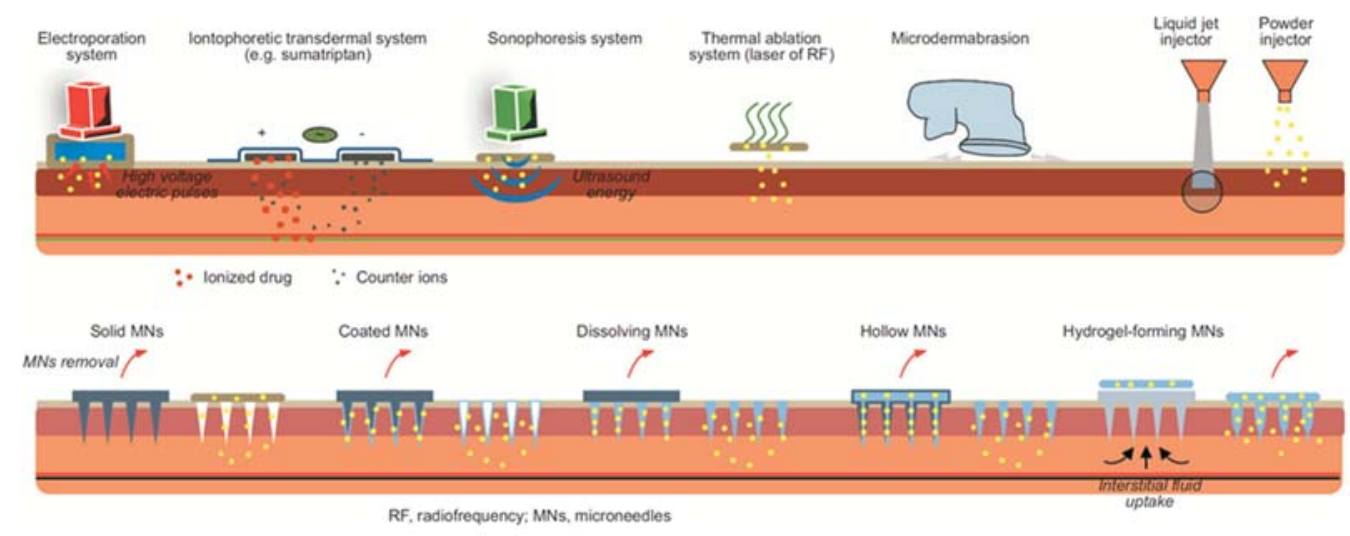

Figure 3. Physical methods for enhancement of percutaneous absorption [1]. Reprinted with permission from ref. [1]. Copyright 2019 Bentham Science.

Electroporation uses high-voltage electrical pulses to generate transient pores in cell membranes through which a wide variety of substances, from small drugs to nucleic acids, can reach the intracellular milieu. Latest examples on skin applications of electroporation techniques include the permeation of low concentration formic and acetic acids for wound disinfection $[16,17]$. This type of electroporation applications was found to promote differential regrowth of dermal fibroblasts and keratinocytes [18].

Iontophoresis is based on use of mild electrical currents to increase skin permeation, mostly by electromigration of ions within the electric field applied, but also by electroosmosis or, to a minor extent, to enhanced passive diffusion. Understandably, this method is better suited for the permeation of charged molecules, whose transport can be modulated by a number of parameters [19]. Ongoing investigational work on biomedical applications of iontophoresis spans from pre-clinical studies on transdermal delivery of anti-hypertensive agents [20], to clinical trials on iontophoresis of treprostinil as a potential treatment for diabetic foot ulcers (DFUs) [21].

Sonophoresis has been also thoroughly explored for enhancement of percutaneous absorption, mainly - but not exclusively - through cavitation or ultrasound (US)-based techniques. Both cavitation [22] and US-based [23] sonophoretic methods have been also recently considered for wound healing approaches, with encouraging results, including in diabetic mice [23]. Of note, care must be taken in order to avoid that the intensity and duration of US irradiation are high enough to cause burns at the irradiation site [1].

In direct methods, though considered a little invasive, pores are created in the SC, through which the entry of solutes into the epidermis and eventually the dermis is forced by means of mechanical, thermal, or pressure-based approaches. Currently, the most popular direct methods include (i) the use of different types of microneedles (MNs)—solid, coated, hollow, dissolving, or hydrogel-forming - to force percutaneous permeation of bioactive compounds, and (ii) microdermabrasion (mechanics-driven) and thermal ablation (heatdriven). Other physical methods have been used to promote percutaneous permeation, though to a lesser extent; one example is that of jet injectors, whereby solid, liquid, or plasma jets force drug delivery by means of the high pressure exerted when they hit the skin [1]. 
Microneedles (MNs)-based approaches are amongst the most widely explored physical methods to promote DTD. In recent years, different types of MN arrays have been thoroughly studied as hurtless alternatives to classical injections, being well advanced in the clinics $[1,24]$. MNs-based technologies are being pushed forward mainly for transdermal delivery of peptides, proteins, and antibodies [25], and for cosmetic applications [26]. Still, the latest reports highlight the therapeutic potential of MNs to tackle non-healing wounds [27]. Based on the promising performance of diverse MN arrays such as Manuka honey, MNs are able to promote healing and exert potent bactericidal action against methicillin-resistant S. aureus (MRSA) [28].

[Photo]thermal ablation techniques are also regarded as a promising way to enhance percutaneous permeation of therapeutics. In classical thermal ablation approaches, components of the outermost skin layer are literally vaporized upon ultrafast exposure to an extremely high $\left(>300{ }^{\circ} \mathrm{C}\right)$ temperature, which disrupts the SC barrier, facilitating subsequent absorption of the drug, typically administered through a transdermal patch. [Photo]thermal ablation methods have been also considered for tackling mild to severe skin infections [29], by means of (i) direct ablation of the microbial pathogens [30], (ii) sensitization of bacterial biofilms to standard antibiotics [31], or (iii) accelerating wound healing [32,33]. One recent example advances a laser-activatable nanosystem able to exert a potent action against multidrug resistant (MDR) bacteria often associated to non-healing wounds, by a combined photothermal effect and controlled release of copper(II) ions [34].

The distinct physical methods mentioned above act through different permeation mechanisms and have been employed alone or combined, with each other or with nonphysical methods, to enhance the absorption of a wide range of APIs, and also cosmeceuticals, through the skin $[1,9,35,36]$.

\subsection{Non-Physical Methods-Nanosized Delivery Systems}

Nanosized [bio]materials and formulations are regarded as the gold standard of nonphysical methods for drug delivery, with emphasis on dermal and transdermal applications. Lipid-based or -inspired nanosystems are by far the most common, covering from the classical examples of nanoemulsions and liposomes (Figure 4) to solid lipid nanoparticles and nanostructured lipid carriers.

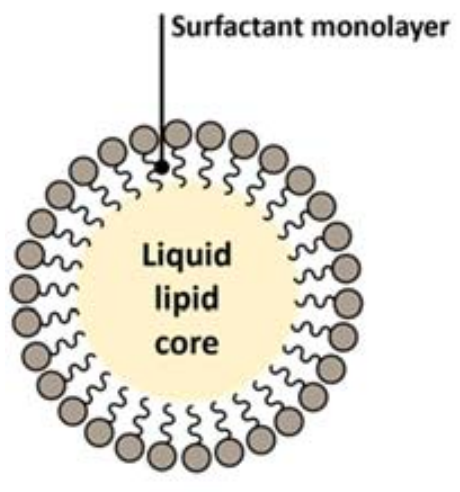

Nanoemulsion

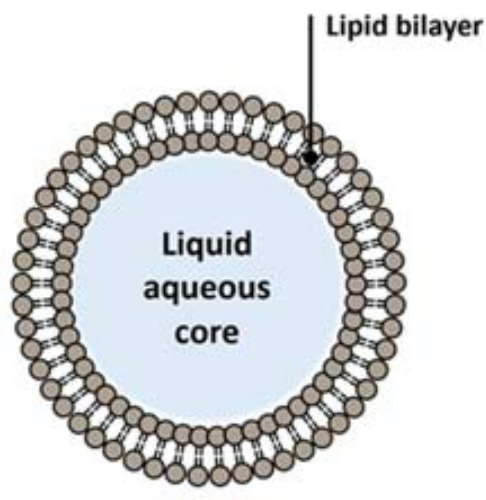

Liposome

Figure 4. General representation of nanoemulsion and liposome.

Nanoemulsions (NEs) allow the dispersion of drug-containing droplets in very high interfacial areas, and their relevance towards the enhancement of percutaneous absorption of either hydrophilic (water-in-oil NEs) or lipophilic (oil-in-water NEs) substances is well established [37,38]. NEs in use or under investigation today offer diverse compositions and degrees of complexity, based on diverse amphiphiles, from natural lipids to synthetic surfactants, and combinations thereof $[37,38]$. Use of essential oils in the formulation of NEs has also been addressed. For instance, a clove oil-based NE was developed to combine the anti-inflammatory and antifungal properties of the main oil component, eugenol, with 
those of the drug cargo, naftifine, used to tackle skin fungal infections [39]. Lately, other types of liposome-inspired vesicles (Figure 5), such as ethosomes, transfersomes, niosomes, among other, have been advanced [1,3,40,41]. Lipid-based/inspired nanosystems stem from ancient knowledge on the value of fatty acids and derived hydrolyzable lipids, especially phospholipids, to enhance percutaneous absorption of a variety of substances for both health- and beauty-care. Phospholipid-based emulsions, as well as micellar and liposomal formulations for skin care are all around us, hence it comes as no surprise that lipid-based/inspired nanocarriers have a prominent role in current approaches for DTD of [bio]pharmaceuticals [1,3,40-43]. Still, nanosystems that do not [exclusively] derive from natural lipids have been thoroughly explored for percutaneous permeation of bioactive molecules; organic nanoformulations comprising either natural or synthetic polymers and/or surfactants other than natural lipids can be found in recent literature, covering distinct types of dendrimers, nanoparticles (NPs), nanoemulsions (NEs), micelles, and hydrogels, for diverse purposes. Likewise, inorganic nanosystems, including metallic, non-metallic, and magnetic NPs, among others, have been employed for DTD of [bio]pharmaceuticals [42,44].

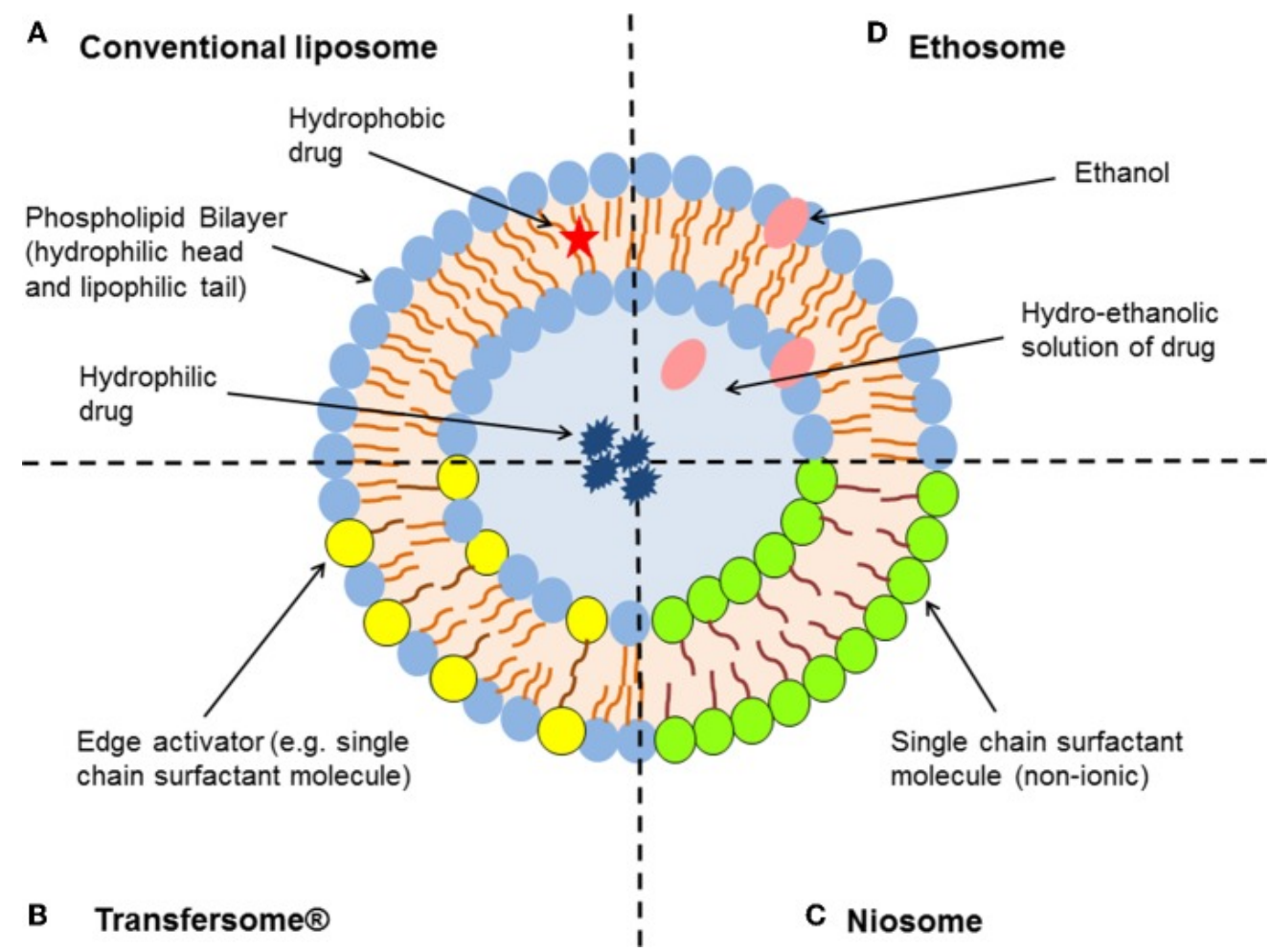

Figure 5. Examples of liposome-inspired vesicles [45]. Reprinted with permission from ref. [45]. Copyright 2015 Hua.

Vesicular nanocarriers (VNs) currently encompass a myriad of different, mostly spherical, structures that share the common trait of having single or multiple bilayer lamellae separating one or more aqueous or hydroalcoholic inner compartments from the outer medium, and which have been widely used for topical disorders and cosmetics $[9,46]$. The best known and most commonly employed VNs are liposomes, spherical colloidal bilayer structures formed spontaneously by amphipathic phospholipids in aqueous environments, which were originally reported in 1965 [47]. However, a variety of liposome-inspired VNs has evolved since, such as:

- ethosomes, soft VNs whose structure is closely related to that of liposomes, the main difference being the presence of ethanol in moderate to high concentrations, which confers the vesicles high malleability and the ability to significantly enhance the percutaneous permeation of highly lipophilic molecules [48]; 
- transfersomes, ultraflexible VNs composed by either phospholipids or other bilayerforming amphipathic molecules packed together with edge activators that decrease the vesicle's interfacial tension; this conveys a very high elasticity enabling a much better permeation through the SC probably via the intercellular route [49];

- niosomes are VNs usually composed by cholesterol and alkyl or polyglycerol-based non-ionic surfactants that usually offer higher osmotic stability and involve lower production costs as compared to phospholipid-based VNs. Yet, like in liposomes, the physical stability of niosomes is not adequate for prolonged storage [50,51].

- other "somes" are continuously emerging as novel VNs for drug delivery, particularly for topical applications. Among others, these comprise: invasomes-terpenecontaining ethosome analogues with enhanced penetration into deeper layers of the skin [52]; aspasomes-multilayered VNs formed by combination of ascorbyl palmitate with cholesterol and charged lipids [53]; and other self-assembling hollow nanostructures based on, e.g., solid crystalline cores (aquasomes), liquid crystalline phases (cubosomes, hexosomes), or hollow coagulated nanoparticles (colloidosomes) [54], as well as polymer-based vesicles (polymersomes) [55].

All these types of artificially produced VNs have been recently explored and optimized to create increasingly efficient formulations for DTD of bioactive molecules and macromolecules. For instance, different hydrogels have been investigated as suitable vehicles for topical delivery of drug-loaded niosomes [56]. In another recent report, an ethosome-based gel showed good performance both in vitro and in vivo for delivery of thymosin $\beta-4$, a protein that is relevant for wound repair [57]. Less common VNs have been lately advanced for diverse purposes, such as unsaturated fatty-acid based nanovesicles (ufasomes) for DTD of terbinafine hydrochloride to address Candida albicans-associated topical fungal infections [58]. Interestingly, when looking at the forefront of VNs-mediated drug delivery, we can witness the increasing relevance of cell-based VNs such as exosomes [59] or outer membrane vesicles (OMVs) from Gram-negative bacteria [60], whose major hallmark is their expectedly high biocompatibility and low immunogenicity. Exosomes are extracellular vesicles that integrate proteins and nucleic acids of their secreting cells, and which can affect function and properties of other cells able to internalize them [59]; as such, recent efforts address their engineering for targeted drug delivery [61,62], also for diverse dermatological applications [63-65] and wound healing [66]. Besides exosomes, OMVs are also becoming prominent actors in several biomedical applications, including recent examples where engineered OMVs from transgenic Escherichia coli have been used for DTD of biopharmaceuticals, alone [60] or in combination with phototherapy [67].

Nanocarriers (NCs) include many other structures besides bilayered VNs, with diverse properties and applications, including targeted delivery of [bio]pharmaceutics (Figure 6) [68]. NCs are typically colloidal particulate systems having at least one dimension not larger than $100 \mathrm{~nm}$. NCs can be categorized in different ways, i.e., based on morphology (nanorods, nanoshells, nanocages, nanostars, etc.), core material (metallic, ceramic, polymeric, carbon-based, lipid-based, etc.), specific physical and/or chemical properties (magnetic, [semi-]conductivity, thermoconductivity, stiffness, porosity, etc.), among other criteria (e.g., surface charge or functionalization) [69]. It should be outlined that most current nanodelivery approaches rely on hybrid/composite systems often comprising inorganic, biopolymeric, and several other natural and/or synthetic organic components, which blur the frontiers between different types of NCs. While nanosized liposomal and liposome-like VNs addressed in the previous section are also NCs, this section is aimed at pinpointing a few recent cases where NCs with non-bilayer structures have been explored for topical delivery focusing on the treatment of skin and soft tissue infections and wound-healing enhancement. 


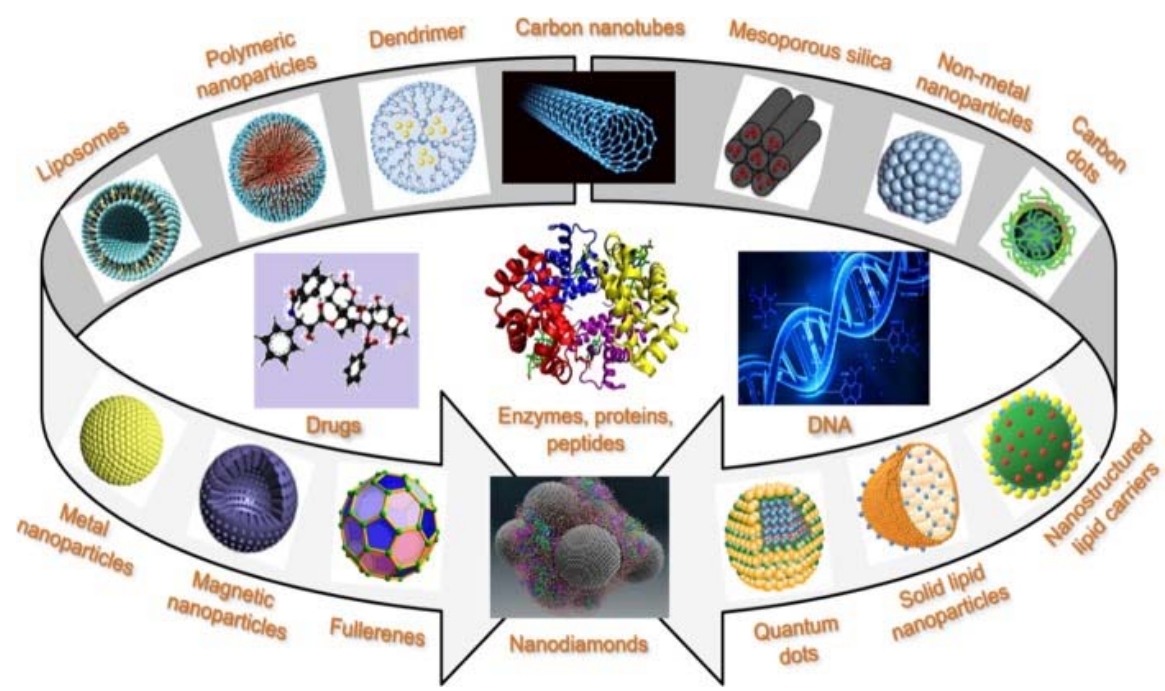

Figure 6. Different types of particulate systems with potential interest as nanocarriers for targeted delivery of drugs and biological macromolecules [68]. Reprinted with permission from ref. [4]. Copyright 2019 American Chemical Society.

Lipid-based NCs, of which solid lipid nanoparticles (SLNs) and nanostructured lipid carriers (NLCs) are the most representative examples (Figure 7), are currently regarded as enhanced alternatives to classical liposomal-based formulations. SLNs emerged as the first-generation of non-liposomal lipid-based nanocarriers, featured by a spherical shape and a payload-containing solid core stabilized by an outer layer lined with surfactants. SLNs offer many advantages over other types of NCs, the main of which are their high biocompatibility and biodegradability, but also high compatibility with a wide range of payloads and cost-effective production, among others. Still, the solid nature of SLNs poses a few limitations, such as low loading capacity and the risks of premature drug release, unexpected gelation, and crystallization upon storage. NLCs emerged to circumvent these hurdles, by offering a nanostructured core containing low-melting point lipids (liquid at room temperature) [70-72].

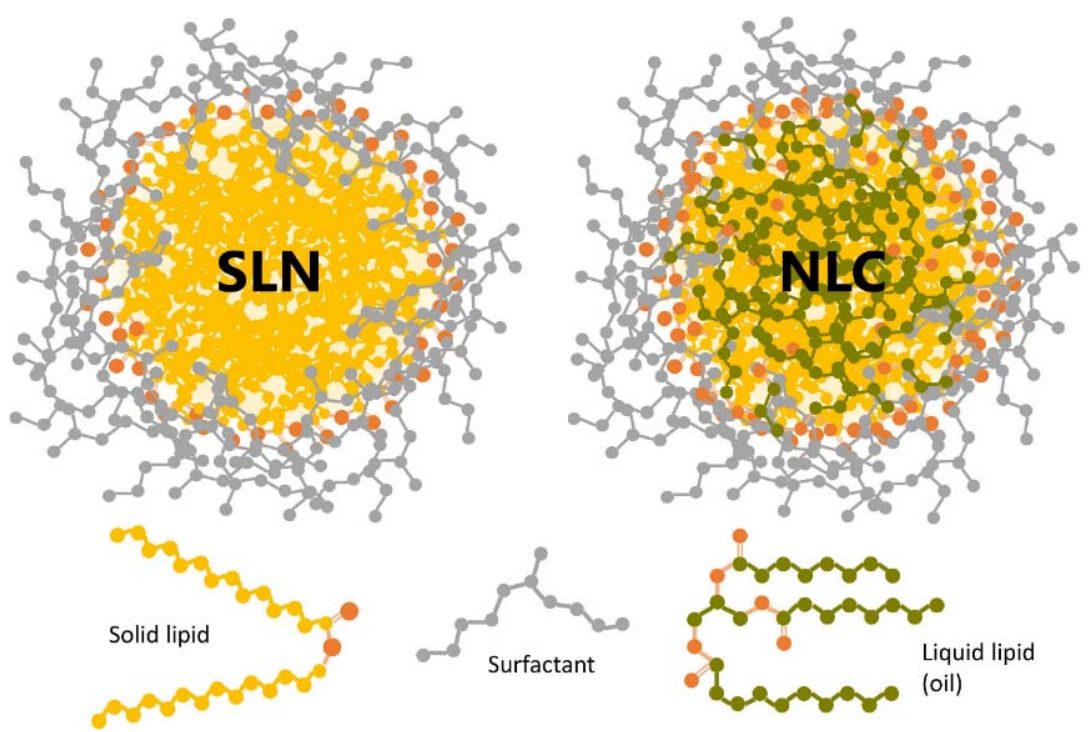

Figure 7. General structures of SLNs and NLCs [72]. Reprinted with permission from ref. [72]. Copyright 2020 Scioli Montoto, Muraca and Ruiz.

The potential of both SLNs and NLCs for drug delivery, including across the formidable obstacles that are the blood-brain barrier and the skin, has been widely addressed [71-73]. 
Promising results have been lately reported to DTD of anti-inflammatory, antibacterial, antiviral, antifungal, antiacneic, and anticancer agents, among others, as nicely reviewed by Souto et al. [73]. Also, SLNs and NLCs have been explored for DTD of cosmetics, with encouraging performances [74]. Importantly, the formulation of SLNs and NLCs for DTD of [bio]pharmaceuticals and cosmeceuticals can be easily tailored according to their specific application and payload [73,74].

SLNs and NLCs are also showing promise to promote skin regeneration [75-77]. Recent investigations focused on DTD of essential oils having healing effects due to either a dual anti-inflammatory/collagenesis-inducing action of the oil itself [78], or to a synergic antimicrobial and healing action elicited by combination of the essential oil with specific components in the lipid nanocarrier (e.g., oleic acid) [79]. Very recently, different SLNs and NLCs have been tested along with NEs for DTD of curcumin, a hydrophobic photosensitive phytomolecule, whose anti-inflammatory, antimicrobial, and healing properties have been known for long [80]. This study revealed that all tested NCs were efficient for photoprotection of the phytopharmaceutical, with NLCs offering the best pharmacological performance, provided the matrix fluidity was tuned for optimized skin occlusion and drug release rate [80]. In line with this, multiple benefits of SLNs/NLCs-mediated delivery of natural and synthetic antimicrobials have been advocated in the recent literature [81-83], including for fighting multidrug-resistant (MDR) infections [84,85]. Thus, a new "nanoantibiotic era" is on the rise [86] that will likely have great impact on the management of complicated skin and skin structure infections (CSSTI), given the unique ability of lipid-based NCs to overcome the skin barrier [87]. One illustrative example is "nanoRIF", a rifampicin-loaded hybrid lipidic/polymeric NC that showed in vivo efficacy against Staphylococcus aureus-associated infection on skin [88].

Non-lipidic NCs enclose a broad variety of organic and inorganic nanomaterials, a few of which are next highlighted for their recent interest for the enhancement of percutaneous permeation:

- dendrimers are hyperbranched arborescent spherical NPs that may be composed by either natural (e.g., amino acid- or peptide-based) or artificial (e.g., ethylene glycolbased) dendrons, whose individual structure and tridimensional arrangement in the final dendrimer have great impact on the physical, chemical, and drug loading/release properties of the whole nanosystem [89]. The biomedical relevance of dendrimers, including for drug delivery, is growing exponentially [90,91], and interest is now falling on topical applications. Latest reports in this regard concern, e.g., use of poly(amidoamine)- or PAMAM-based dendrimers for enhanced skin permeation of the chlorhexidine digluconate antiseptic [92], or dermal delivery and follicular targeting of the antiacneic agent adapalene [93].

- [bio]polymer-based NCs, encompassing [bio]polymeric NPs, films, gels, nanofibers, among others, have been thoroughly investigated for drug delivery applications [94], including for topical use [95]. Natural polymers such as chitosan, poly(glycolic acid), poly(lactic acid), hyaluronic acid, and poly(arginine) are amongst the most popular components of polymeric NCs, given their biocompatibility and biodegradability, along with their chemical "flexibility" to enable the production of a wide range of multi-component customized stimuli-responsive nanomaterials [95]. Chitosan-based polymeric NCs have been thoroughly explored for topical applications, given the intrinsic antimicrobial and healing properties of chitosan [96]. One recent example concerns development of a chitosan/carboxymethyl cellulose-based nanogel for transdermal co-delivery of atorvastatin and Nigella sativa oil for wound management, taking advantage of the anti-inflammatory, immunomodulatory, antioxidant, and antibacterial properties of both bioactive cargoes; in vitro permeation, cytotoxicity, healing, and bactericidal activity assays delivered quite promising results [97]. Many other polymer-based nanomaterials have been explored in recent years for topical applications from, e.g., extracellular matrix-mimicking nanofibrous scaffolds [98] to promote accelerated healing of chronic wounds. 
- inorganic NCS integrate metal-, metal oxide-, and mesoporous silica-based NPs as the most popular examples, although other nanosystems, such as inorganic polymerbased NCs, carbon-, carbon oxide-, or black phosphorus-based nanomaterials, also fit this category [99-102]. Although the majority of inorganic NCs in drug delivery, including DTD, has been addressed to cancer theranostics [103] they have also been explored for antimicrobial therapies [104], where silver-based NPs (AgNPs) occupy a prominent role, given the intrinsic antibacterial properties of silver [52,105]. For instance, AgNPs synthesized from silver nitrate in the aqueous extract of a medicinal plant (Acanthospermum australe) used in South America to treat cSSTI, were recently reported to have potent wide spectrum antimicrobial activity [106]. Yet, AgNPs, as well as other inorganic NPs such as zinc oxide-based ones, may pose toxicity issues for dermatological and dermocosmetic use [107]. As such, recent reports on use of AgNPs, or even of other inorganic NCs, for DTD of [bio]pharmaceuticals are relatively scarce. Notwithstanding, graphene oxide-based NCs have been lately highlighted for topical applications [108], including as bioactive agents able to tackle cSSTI per se $[109,110]$. Other carbon-based inorganic NCs have also been explored to tackle skin disorders, with emphasis on wound healing and control of cSSTI, as recently revised elsewhere [111]. Additional examples on use of inorganic NCs for DTD of [bio]pharmaceuticals mainly address combination with physical methods, in particular with microneedle-based technologies [112-114].

\subsection{Chemical Permeation Enhancers}

As already mentioned, chemical permeation enhancers (CPEs) are molecules able to temporarily alter the structure of the $\mathrm{SC}$, thus enhancing the percutaneous permeation of different substances. The performance of a CPE depends on its ability to both efficiently partition from the applied medium into the skin lipid layer and interact with the constituents of this layer, causing momentary but significant perturbations that lead to the desired higher permeability of the SC. While the solution-to-SC partition is influenced by the lipophilicity of the CPEs, the size and structure of the latter dictate the permeation enhancement pathway(s) (Table 2, Figure 8). Thus, some CPEs, like alcohols and polyols, act mainly as solvents that increase the solubility of the drug and its partitioning into the SC, whereas other solvents used as CPEs, as dimethylsulfoxide, are further able to extract lipid molecules from the SC, creating channels that turn the SC more permeable. Other CPEs, like fatty acids or their esters, are able to insert into the bilayer structures of skin lipids, altering their ordered packing and thus increasing permeability $[10,115,116]$. Relevantly, though CPEs are usually associated to lipophilic or amphiphilic organic compounds (Table 2), water is the safest and most widely employed CPE for dermatological and dermocosmetic applications; water offers the simplest way to deliver hydrophilic compounds across the skin, but is also able to enhance the permeation of lipophilic ones, as it can both interact with the polar head groups in the SC lipid bilayer and disrupt hydrogen bonding (e.g., in proteins) in intra- and intercellular compartments of the skin [116].

Table 2. Examples of different classes of CPEs and their recognized modes of action [116]. Adapted from the permission of ref. [116]. 2018 Haque and Talukder.

\begin{tabular}{ccc}
\hline CPE Class & Example(s) & Mode(s) of Action \\
\hline $\begin{array}{c}\text { low molecular weight } \\
\text { linear alcohols }\end{array}$ & $\begin{array}{c}\text { ethanol } \\
\text { hexanol } \\
\text { octanol }\end{array}$ & $\begin{array}{c}\text { extraction of intercellular lipids } \\
\text { increased solubility/partitioning of the solute into the SC }\end{array}$ \\
\hline glycols and polyols & $\begin{array}{c}\text { propylene glycol } \\
\text { polyethylene glycol }\end{array}$ & increased solubility/partitioning of the solute into the SC \\
\hline esters & octyl salicylate & accumulation in the SC lipid bilayer enhancing solute diffusivity \\
\hline amides & laurocapram $\left(\right.$ Azone $\left.^{\circledR}\right)$ & disruption of the ordered packing of the bilayers of skin lipids \\
\hline
\end{tabular}


Table 2. Cont.

\begin{tabular}{|c|c|c|}
\hline CPE Class & Example(s) & Mode(s) of Action \\
\hline sulfoxides & $\begin{array}{l}\text { dimethylsulfoxide } \\
\text { dodecyl methyl sulfoxide }\end{array}$ & $\begin{array}{c}\text { extraction of intercellular lipids } \\
\text { increased solubility/partitioning of the solute into the SC } \\
\text { interaction with keratin and/or corneocytes, and with the polar head } \\
\text { groups of the SC lipid bilayer }\end{array}$ \\
\hline pyrrolidones & $\begin{array}{l}N \text {-methyl-pyrrolidone } \\
\text { 2-pyrrolidone }\end{array}$ & $\begin{array}{l}\text { interaction with keratin and/or corneocytes, and with the polar head } \\
\text { groups of the SC lipid bilayer }\end{array}$ \\
\hline terpenes & $\begin{array}{c}\text { menthol } \\
\text { limonene } \\
\text { nerol }\end{array}$ & disruption of the ordered packing of the bilayers of skin lipids \\
\hline fatty acids & oleic acid & disruption of the ordered packing of the bilayers of skin lipids \\
\hline fatty esters & $\begin{array}{l}\text { isopropyl myristate } \\
\text { propylene glycol monocaprylate } \\
\text { propyleneglycolmonolaurate }\end{array}$ & $\begin{array}{c}\text { extraction of intercellular lipids } \\
\text { phase separation }\end{array}$ \\
\hline \multirow{3}{*}{ surfactants } & sodium lauryl or dodecyl sulfate (anionic) & $\begin{array}{l}\text { interaction with keratin and/or corneocytes } \\
\text { incorporation into the SC lipid bilayer and induction of lamellar phases }\end{array}$ \\
\hline & quaternary ammonium salts (cationic) & $\begin{array}{l}\text { significant disruption of the ordered packing of the bilayers of } \\
\text { skin lipids }\end{array}$ \\
\hline & $\begin{array}{l}\text { cetyl or stearyl alcohol } \\
\text { (nonionic) }\end{array}$ & disruption of the ordered packing of the bilayers of skin lipids \\
\hline ether alcohols & 2-(2-ethoxyethoxy)ethanol (Transcutol ${ }^{\circledR}$ ) & $\begin{array}{c}\text { insertion between the polar head groups of the skin lipid bilayers, } \\
\text { inducing swelling of the SC }\end{array}$ \\
\hline
\end{tabular}

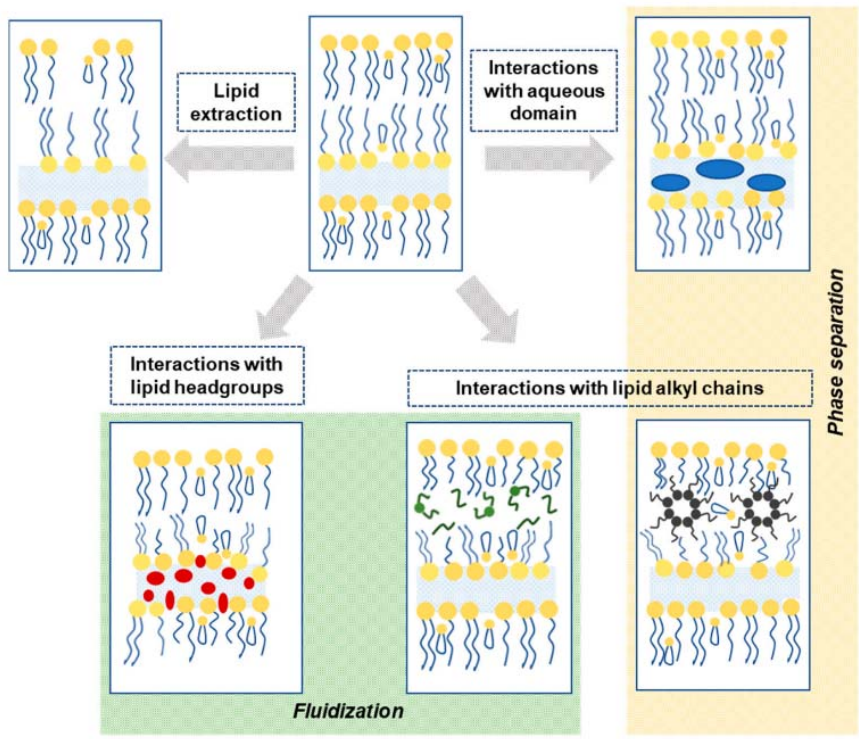

Figure 8. Schematic view of the modes of action of CPEs [4]. Reprinted with permission from ref. [4]. Copyright 2021 MDPI.

While physical and nanotechnological approaches like those addressed in previous sections undeniably lie at the forefront of dermal and transdermal drug delivery research, CPEs remain the simplest and most cost-effective way to permeate different solutes across the skin, and their use is widely disseminated [116]. This explains the strong interest towards a better understanding of their modes of action [10,117] and on development of novel CPEs, searching for greener and more biocompatible alternatives, such as those derived from essential oils [118] or amino acids [4].

The wide diversity and relevance of CPEs recently motivated Bozdaganyan and coworkers to create an Open Access CPEs database, CPE-DB (http: / / intbio.org/cpedb/, last accessed on 4 November 2021), that includes ca. 650 CPEs covering all classes shown in Table 2 and a few more miscellaneous structural types [119]. 
Amidst the chemically diverse CPEs known to date, examples are found that can be categorized as ionic liquids (ILs), where organic cations are paired with organic or inorganic anions [120]. One emblematic IL that is widely employed as a topical antiseptic with high percutaneous permeation is cetylpyridinium chloride (CPC) [11], but others have also shown high potential as CPEs for DTD applications, including ILs based on natural building blocks like choline geranate (CAGE) $[15,121]$ or obtained by pairing the [ionizable] drug itself with a proper counterion as in, e.g., dodecyldimethylammonium ibuprofenate [13]. Undeniably, ILs are rising stars for a broad variety of applications. As recently advocated, "The time is now for ionic liquids" [122]; the next section emphasizes this is also true for DTD of [bio]pharmaceuticals.

\section{Ionic Liquid-Based Approaches in Dermal and Transdermal Drug Delivery \\ 3.1. A Bird's Eye View on Ionic Liquids}

ILs are salts formed by organic cations and organic or inorganic anions, which possess unique physical and chemical properties that differentiate them from the other ("conventional") salts. The most emblematic feature of ILs is their very low melting points (usually, but not necessarily, below $100{ }^{\circ} \mathrm{C}$ ), due to a lack of ion symmetry and to low charge density, which results in Coulombic interactions in the solid phase that are weaker than those in other salts [14]. Given the huge number of possible cation/anion combinations, reports to date cover an immense panoply of different ILs that can be classified in many different ways, depending on the classification criteria (Figure 9), as thoroughly reviewed elsewhere [123]. In general, three generations of ILs have been recognized, going from the earlier examples of ILs proposed as "greener" surrogates of classical organic solvents to the next generation of ILs whose chemical and physical properties were adjustable to their specific applications (task-specific ILs, or TSILs), and finally to ILs displaying low toxicity, biocompatibility, biodegradability and, in some cases, even bioactivity [120,121,123-125].

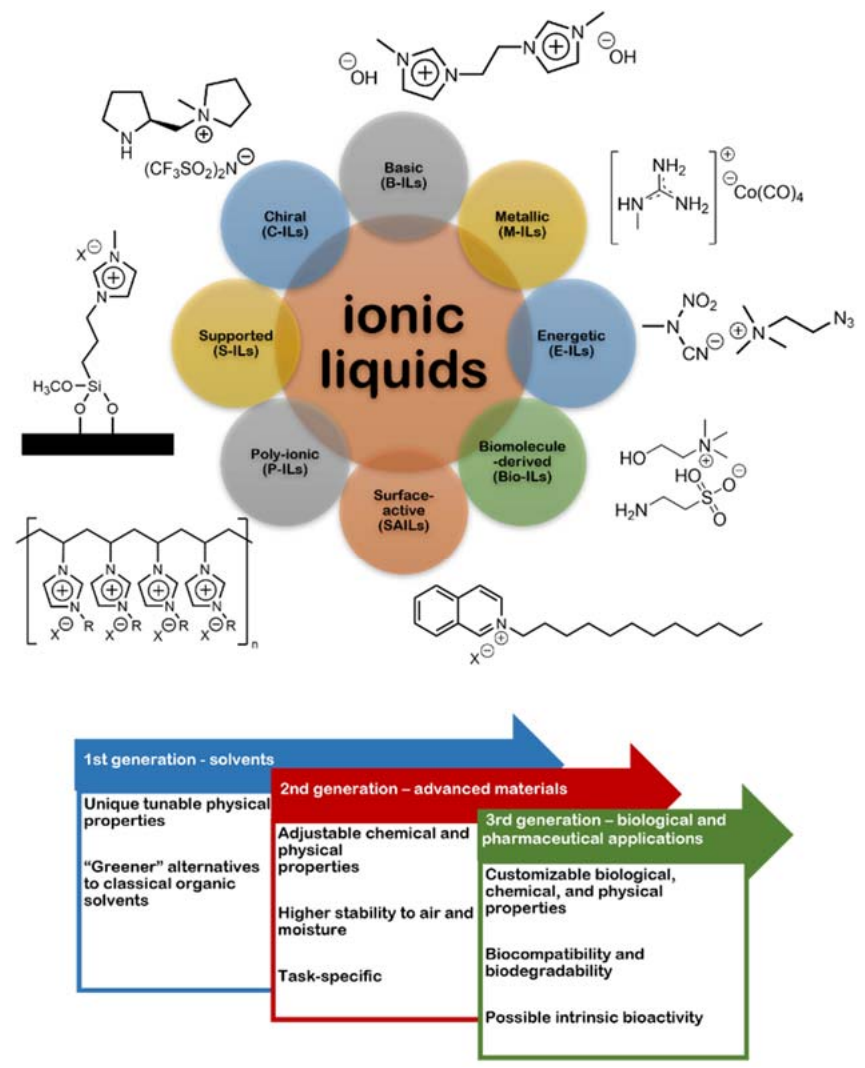

Figure 9. A few examples of different types of ILs, and their three recognized generations. 
ILs are particularly appealing for pharmaceutical applications, given their (i) noncrystalline nature, avoiding fluidity/polymorphism-related liabilities of many drug formulations, and (ii) easy customization and adjustable-properties, through a sensible choice of the ion components $[12,124,125]$. Hence, ILs properties such as vapor pressure, thermal stability, chemical and electrochemical stability, polarity, solubility, amphipathicity, and even bioactivity, can be finely tuned [14]. For instance, ionizable active pharmaceutic ingredients (APIs) have been paired with selected counterions to deliver ILs, including room-temperature ILs (RTILs), that possess intrinsic bioactivity $[13,125,126]$. Also, amphipathic ILs have been developed that are miscible in a wide range of solvents and display surface activity (surface-active ILs, or SAILs), representing a new class of surfactants, some of which possess interesting biological properties, such as antimicrobial action. Relevantly, though emerging from the 2nd generation of ILs for applications as, e.g., emulsifiers, SAILs enclose a tremendous potential for biomedical and pharmaceutical applications $[14,126,127]$.

\subsection{Ionic Liquids in Skin Permeation-A Closer Look at the Past Couple of Years}

Over the last decade, the interest on using ILs to promote topical delivery of bioactive molecules and APIs has been steadily growing. For instance, several reports from 2010 to 2018 highlight the promising role of ILs, most of which are imidazolium-based, towards enhanced percutaneous permeation of drugs and bioactive compounds as diverse as acyclovir, methotrexate, dantrolene sodium, etodolac, 5-fluoroacyl, salicylic acid, caffeine, dencichine, peptides and proteins. Interestingly, some of these reports address studies on skin permeation of API-ILs, i.e., ILs resulting from combination of an ionizable drug (or API) with an adequate counterion (e.g., lidocaine chloride), or even of two ionizable APIs with opposed polarities (e.g., lidocaine docusate, lidocaine ibuprofenate, or lidocaine/etodolac) [128,129].

The mechanisms through which ILs or API-ILs display enhanced skin permeation are not fully unveiled and are primarily - though not exclusively—dependent on the specific structural and physico-chemical features of the IL. Thus, the CPE action of hydrophilic ILs (e.g., 1-ethyl-3-methylimidazolium-based) has been mostly ascribed to their role as polar enhancers able to (i) increase solubility and partition of hydrophilic drugs, and /or (ii) fluidize the SC by disrupting the tight packing of both proteins and lipids (at the headgroups level-Figure 8). In turn, hydrophobic ILs, many of which are SAILs (e.g., CPC, 1-dodecyl-3-methylimidazolium-based ILs), may exert their skin permeation action by (i) increasing solubility and partition of hydrophobic drugs, (ii) inserting into the SC lipid bilayers, causing a disruption of the ordered packing of the phospholipid bilayers or even phase separation or induction of lamellar phases (Figure 8), and/or (iii) extracting SC lipids [124,128-131]. Interestingly, SC lipid extraction followed by replacement of the extracted lipids with the IL and water has been recently advanced as the mechanism by which CAGE enhances the skin permeation of macromolecules like dextran [132].

ILs alone, and in combination with other percutaneous permeation methods, have been lately explored for DTD of diverse [bio]pharmaceuticals, so a few illustrative examples reported in the past couple of years are next highlighted.

\subsection{IL-Based Topical Delivery Approaches for Small Bioactive Compounds}

Non-steroidal anti-inflammatory drugs (NSAIDs), often ibuprofen but also others, are amongst the most common low molecular weight bioactive compounds that have been explored for IL-mediated topical delivery $[125,130]$. In this connection, Wu et al. have recently investigated the role of the counterion in the physico-chemical and biological properties of ibuprofen-derived ILs, with emphasis on transdermal delivery applications [133]. This study, which integrated nine different ibuprofen-based ILs using tetraalkylammonium and tetraalkylphosphonium counterions, confirmed the superior permeation of the ILs accross an in vitro skin model as compared to the free drug, highlighting the didecyldimethylammonium and tetrahexylammonium counterions as the most beneficial for such an effect [133]. Moreover, it was possible to establish a correlation between percutaneous 
permeation efficiency and (i) ILs' lipophilicity (higher $\log \mathrm{P}$ and lower water solubility), and (ii) strength of ionic association between the anionic form of the drug and the cationic counterion [133]. In another latest study, Yuan et al. established that even minor amounts of choline/amino acid-based ILs, namely, cholinium glycinate and cholinium alaninate, contribute to a significant enhancement of the water solubility and permeation of ibuprofen across a model skin membrane, along with the advantage of showing low toxicity to mouse embrionyc fibroblasts [134]. Cholinium-based ILs have also been the focus of another quite interesting recent approach for enhanced DTD of NSAIDs, by Silvestre and co-workers [135]. These authors synthesized a series of API-ILs derived from ibuprofen, ketoprofen, and (S)-naproxen, using cholinium as the counterion, (Figure 10a) whose aqueous solubility were about one order of magnitude higher than those of the free NSAIDs. Moreover, incorporation of the API-ILs into bacterial nanocellulose afforded flexible and transparent membranes with adequate properties for use as DTD systems, while offering equal anti-inflammatory potency and a faster drug release as compared to loading of the parent NSAIDs alone [135].

(a)

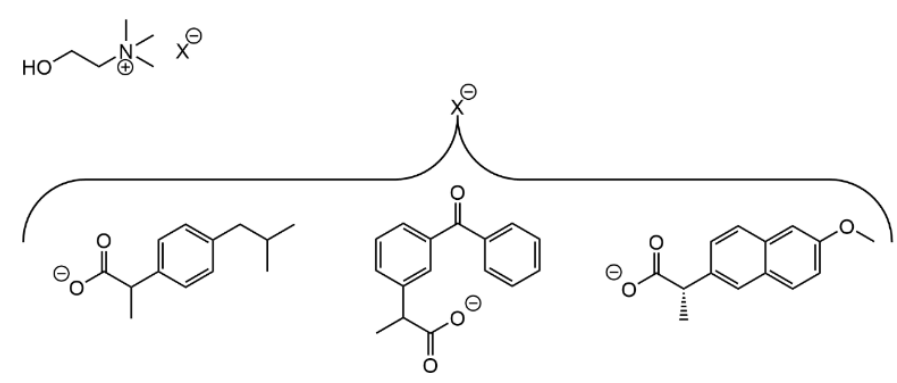

(b)<smiles>CC[NH+](CC)CC(=O)Nc1c(C)cccc1C</smiles>

Figure 10. Examples of NSAIDs-derived ILs advanced for transdermal delivery: (a) ILs produced by pairing the cholinium cation with the anionic forms of (from left to right) ibuprofen, ketoprofen, and (S)-naproxen [135]. Adapted with permission from ref. [135]. Copyright 2019 American Chemical Society; (b) dual-action IL composed by the cationic form (conjugate acid) of lidocaine and the anionic form (conjugate base) of diclofenac [136]. Adapted with permission from ref. [136]. Copyright 2020 Springer Nature.

NSAIDs other than the profens (2-aryl-propionic acid derivatives) have also been the subject of recent investigations addressing IL-mediated topical delivery. For instance, Carneiro and co-workers have reported the synthesis and characterization of diclofenac imidazolium monohydrate, an API-IL with increased water solubility as compared to the parent API that the authors advocate as promising for transdermal delivery approaches, although its cytotoxicity remains to be evaluated [137]. Current research is also addressing pairing diclofenac with local anesthetics or analgesics to afford dual-action ILs that are next embedded into suitable materials for topical application. For example, Suksaeree and Maneewattanapinyo have recently reported the ion-pair reaction between lidocaine hydrochloride and diclofenac sodium (Figure 10b) to afford a dual-action diclofenac/lidocaine IL that was next incorporated into a polymer matrix suitable for fabrication of transdermal patches [136]. The authors investigated the influence of the polymer matrix composition onto IL loading capacity, controlled drug release rate, and drug crystallization, advancing a few guidelines for future development of similar formulations [136]. The same research group further tested the controlled release of the diclofenac/lidocaine IL from gelatin/poly(vinyl alcohol) transdermal patches, which conveyed high release rates for both APIs and suitable physicochemical and stability features for pharmaceutical applications [138]. 
Incorporation of lidocaine/NSAIDs-based dual-action ILs into polyvinylidene fluoride/hyaluronic acid-based membranes has also been addressed by Abednejad et al., who found (i) an up to 470-fold enhancement of the water solubility of the ILs as compared to the free APIs, (ii) improved release of the APIs from the IL-loaded membranes, (iii) suitability of the IL-loaded membranes for use as wound-dressings, (iv) enhanced membrane adhesion and viability of membrane-adhered fibroblasts, and (v) anti-inflammatory activity similar to that of the free APIs [139].

IL-based strategies have also been lately addressed for enhanced skin permeation of other types of small bioactive compounds, from anticancer or neuroactive drugs to antioxidant or other anti-ageing agents, among others. For instance, amino acid-based ILs have been recently considered for topical treatment of cancer. In this regard, Zheng et al. have recently screened 15 methyl amino acid ester hydrochlorides as potential CPEs for model drugs like 5-fluoroacyl, and found that the L-proline and the L-leucine-based ILs were the most promising of the set, owing their percutaneous permeation ability to a combined lipid fluidization and lipid extraction effect [140]. Another amino acid, taurine, has been recently investigated for production of ILs with intrinsic antitumor activity and enhanced percutaneous permeation [141]. To this end, taurine was paired with bioactive alkaloids, namely, L-carnitine and betaine, affording ILs with high thermal stability, biocompatibility, and in vitro antitumor activity. The taurine-derived ILs were further shown to enhance percutaneous permeation of both insulin and dextran, possibly via a lipid extraction mechanism [141].

IL-mediated topical delivery of neuroactive molecules such as the memory-enhancing agents donepezil and nobiletin has been equally investigated in the last couple of years. $\mathrm{Wu}$ et al. ion-paired donepezil with docusate, ibuprofen, and unsaturated fatty acids, producing ILs that were thoroughly characterized regarding their structural and physicochemical properties, as well as in vitro antiproliferative action on human neuroblastoma cells, acetylcholinesterase (AchE) inhibitory activity, and ability to permeate through model blood-brain and skin barriers [142]. Additional skin permeation assays were carried out using IL-loaded adhesive transdermal patches, and-taken together-results highlighted a higher skin permeability of donepezil $\alpha$-linolenate and docosahexaenate as compared to free donepezil, which could be further enhanced by loading the ILs onto the adhesive patches [142]. Moreover, despite having slightly decreased anti-AchE activity, the ILs had similar or lower cytotoxicity than the free drug [142].

IL-promoted DTD of another memory-enhancing molecule, the poorly water-soluble flavonoid nobiletin, has been also tested recently by Hattori et al., using choline and geranic acid (CAGE); this IL established multiple hydrogen bonds with the drug, contributing to a substantial increase of its solubility [143]. Additionally, in vitro and in vivo assays confirmed the superior performance of CAGE, as compared to other CPEs, in enhancing the percutaneous permeation of nobiletin, whose bioavailability via the transdermal route was found to be 20-fold higher than oral administration of the crystalline form of the drug [143].

ILs have also been lately explored as potential CPEs of anti-ageing molecules, such as $\alpha$-lipoic acid and other natural antioxidants. Fang and co-workers prepared different ILs by acid-base combination of $\alpha$-lipoic acid with a series of amines, and the ILs subsequently formulated with a liquid oil mixture to form water-in-oil NEs [144]. Transdermal permeation of the NEs was assayed in vitro on whole skin, and on medical tape-stripped epidermal and dermal skin layers, and these assays, together with additional structural and rheological studies, showed that different IL-skin layers' affinities accounted for distinct skin permeation and retention ability [144]. Still, globally, the IL-based NEs not only provided enhanced solubility and protection to this somewhat unstable drug, but also showed very good in vivo action against photo-induced skin ageing and collagen loss in rats [144].

Caparica et al. have equally advanced IL-based emulsions as promising tools for enhanced solubility and percutaneous permeation of natural antioxidants relevant in cosmetics, namely, ferulic acid, caffeic acid, $p$-coumaric acid, and rutin [145]. These authors explored eight different ILs, encompassing amino acids, choline, and imidazole building 
blocks, and, after setting their highest nontoxic concentrations, based on their in vitro toxicity to human keratinocytes, determined their concentration-dependent ability to solubilize the antioxidants, and the physicochemical properties of IL-loaded oil-in-water NEs. This showed that incorporation of the ILs in the NEs conveyed a higher drug load in all four cases, holding great promise for future exploration of these formulations, especially those based on imidazolium glycinate, for DTD of natural anti-ageing agents as those covered in the study [145].

Also with a focus on dermal care applications, Chantereau et al. reported, in early 2020, bioactive ILs obtained by pairing cholinium cations with anionic forms of B-complex vitamins, namely, nicotinate (vitamin B3), pantothenate (vitamin B5), and pyridoxilate (vitamin B6 co-factor) [146]. These vitamin B-derived ILs (Figure 11) showed significantly enhanced solubility as compared to the free vitamins, and their subsequent loading onto bacterial nanocellulose delivered flexible thermostable and nontoxic membranes with enhanced rehydration capacity as compared to non-IL-loaded bacterial cellulose. Moreover, in buffer, the release of the vitamin B-based ILs was faster and more extensive than that of the free vitamins [146].
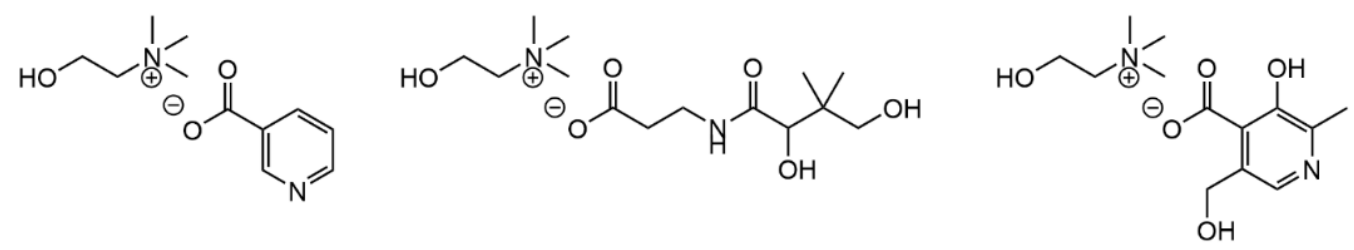

Figure 11. ILs combining the cholinium cation with the anionic forms (conjugate bases) of (from left to right) nicotinic acid (vitamin B3), pantothenic acid (vitamin B5), and pyridoxic acid (vitamin B6 co-factor), reported by Chantereau et al. [146]. Adapted with permission from ref. [146]. Copyright 2020 Elsevier.

One of the current greatest health concerns worldwide is that of MDR infections. In line with this, several latest reports address the use of IL-based strategies for topical application of diverse anti-infective agents to treat mild to complicated skin infections of viral, bacterial, or fungal origin. One example concerns acyclovir, whose clinical relevance in the management of herpes virus infections, including herpes labialis, is hampered by its very low water solubility. Hence, Islam et al. have recently reported the preparation of "ILs-in-oil" microemulsions (MEs) by combining hydrophilic choline-based ILs ("water"like) with a mixture of the SAIL choline oleate and sorbitan laurate ("oil" phase), which allowed enhanced permeation of acyclovir through pig skin while showing no significant skin irritation [147]. The same authors have also investigated ternary systems comprising ethanol, isopropyl myristate, and choline/amino acid-based ILs, also with encouraging results for solubilization and skin permeation of acyclovir [148].

Many ILs have also intrinsic antimicrobial activity, which is putting them under the spotlight for the management of skin infections, including cSSTI. Imidazolium-based ILs have been for long known to possess antimicrobial action [12], although this has been occasionally hampered by their cytotoxicity [149]. Still, imidazolium-based ILs have been used to prepare novel formulations showing encouraging features to be advanced as safe transdermal delivery systems, e.g., IL-in-oil MEs based on 1-ethyl-3-methylimidazolium acetate [150], or intrinsic antibacterial and antibiofilm activity, as is the case of 1-butyl-3methylimidazolium hexafluorophosphate-incorporated PLGA NPs developed by Takahashi and co-workers [151]. CAGE is another IL well-known for its activity as a CPE that was recently reported to display strong and broad spectrum antibacterial and antibiofilm activity, including against clinical isolates and MDR strains of bacterial species belonging to the so-called ESKAPE group (comprising Enterococcus faecium, Staphylococcus aureus, Klebsiella pneumoniae, Acinetobacter baumanii, Pseudomonas aeruginosa, and Enterobacter spp.) [152]. The antibiofilm action of CAGE was further investigated in vitro on biofilms of methicillin-sensitive $S$. aureus, revealing that the neat IL probably acts by contact killing, 
eradicating even $72 \mathrm{~h}$-grown biofilms in less than a minute [152]. CAGE also shows promise for tackling skin fungal infections, as recently reported by Qi and co-workers [153]. These authors combined different antimicrobial ILs with the antifungal drug ketoconazole, and found CAGE as the most effective in both promoting deep skin penetration of the drug, and displaying a synergistic antifungal action in vitro against Trichophyton interdigitale [153].

Other IL-based approaches that are emerging in the latest literature are aimed at addressing topical administration of different types of anti-infective agents. For example, Zhang et al. have developed ME formulations based on the 1-hydroxyethyl-3methylimidazolium chloride and lidocaine ibuprofenate ILs that were able to improve the transdermal permeation of the antimalarial drug artemisinin via disruption of the regular arrangement of keratin in the SC [154]. In another example, the 3-hexyl-1-vinylimidazolium bromide IL was employed in the production of a polymerized IL (P-IL) next used to fabricate MNs both possessing intrinsic antimicrobial activity and loaded with salicylic acid, for the topical treatment of skin infections associated to Propionibacterium acnes. These MNs were able to promote painless and prolonged DTD of salicylic acid, with enhanced anti-acne effects in both ex vivo and in vivo experiments [155].

Altogether, these examples highlight the tremendous chemical space that is to be explored regarding use of ILs for topical drug delivery, with focus on anti-infective approaches to face the rising menace of MDR pathogens. ILs are opening new avenues for the post-antibiotic era, as recently highlighted by Bento et al., [156] and one of those avenues may pass by IL-based approaches for topical delivery of antimicrobial and wound-healing peptides.

\subsection{IL-Mediated Percutaneous Permeation of Biomacromolecules}

One the general requisites for a molecule to be able to transpose the SC barrier to reach the viable epidermis and, eventually, deeper skin layers, is a maximum molecular weight of $1 \mathrm{kDa}$, which means that, unaided, [bio]macromolecules are unable to efficiently permeate across the skin [6]. This size limitation, along with solubility and stability issues, explains why many of the physical, nanotechnological, and chemical approaches addressed in Section 2 have been widely employed to enhance the percutaneous permeation of biomacromolecules such as nucleic acids, oligonucleotides, proteins, and peptides [6,157,158].

In connection with the above, ILs are also showing remarkable capabilities as new chemical tools for the DTD of polysaccharides, nucleic acids, proteins, and peptides. The potential of IL-mediated DTD of polysaccharides and proteins has been already hinted in the previous sub-section, when highlighting taurine-based ILs that, besides displaying intrinsic antitumoral activity, were also able to promote transdermal delivery of insulin and dextran [158]. Yet, polysaccharides like dextran, and related structures, seldom are the object of percutaneous permeation enhancement efforts. Still, Wu et al. have recently explored the potential of eight different choline-based ILs to mediate the DTD of a glycosaminoglycan, hyaluronic acid, to reduce skin dehydration [159]. The ILs were prepared via acid-base neutralization reactions using choline and selected natural acids (malic, sorbic, maleic, succinic, lactic, geranic, citric, and oleic), and cholinium citrate was found as the most capable of promoting penetration into deeper skin layers and, along with cholinium maleate, significantly reducing skin dehydration [159].

Choline-based ILs have been also lately explored for DTD of nucleic acids by Mitragotri and co-workers [160]. These authors prepared six ILs by a 1:2 cation/anion ratio mixing of cholinium bicarbonate, as the cation donor, with geranate, dimethylacrylate, isovalerate, isopropanoate, phosphate, or biphenyl-3-carboxylate anions, and next tested the ILs either individually or in different combinations, for their ability to promote DTD of a siRNA with therapeutic potential to tackle plaque psoriasis. The mixture combining CAGE and cholinium phenylpropanoate was the most efficient permeation enhancer that further showed high stability [160]. Additional in vitro and in vivo assays focused on this combination proved it as safe and able to efficiently silence the deviant gene, with observable decrease in psoriasis-related traits, such as thickened epidermis, inflammation, and hyperkeratosis, as compared to control mice [160]. Mitragotri's group further investigated 
how ILs might contribute to the stabilization of framework nucleic acids (FNAs), whose emerging role as the next generation of precision-tailored and safe NCs for gene therapy of skin diseases is hampered by stability and percutaneous permeation limitations [161]. The authors combined the cholinium cation with the conjugate bases of six natural acids, namely, citronellic, glutaric, glycolic, octanoic, hex-2-enoic, and oct-2-enoic acids, via salt metathesis, and the six ILs thus obtained were tested in vitro and ex vivo for their ability to stabilize and permeate FNAs. Cholinium octanoate showed the most encouraging performance, being able both to keep the FNA NCs stable up to one week at room temperature, and to promote their delivery into the deeper layers of porcine skin [161].

Proteins and peptides are, by far, the most widely and deeply studied biomacromolecules, given their multiple pharmaceutical and biomedical applications, stemming from their broad range of structural, physicochemical, and biological properties, associated to a high level of specificity, thus representing the majority of biopharmaceuticals approved for therapeutic use [162]. Yet, most protein and peptides pose many challenges for therapeutic applications, mostly related to their low bioavailability and in vivo stability, which underpins intensive research on strategies for efficient protein and peptide delivery specifically aimed at oral and topical administration routes [158,163]. IL-mediated delivery of proteins has been investigated in recent years, with emphasis on insulin, since topical administration of this protein is highly convenient to promote higher comfort and compliance in diabetic patients. Favorable insulin permeation data were recently reported by Mitragotri and co-workers when using CAGE or taurine/carnitine ILs as, respectively, part of a biodegradable polymeric patch for transmucosal delivery [164], or percutaneous permeation enhancer [140]. Balcão and co-workers have also investigated the adequacy of CAGE and choline oleate ILs, prepared in a 1:2 cation/anion ratio, for potential use in transdermal delivery of insulin [165]. The ILs were evaluated regarding cytotoxicity, genotoxicity, oxidative stability, and ability to enhance insulin percutaneous permeation. CAGE presented the best profile, and was next incorporated in an optimized biopolymer formulation, affording a transdermal patch that efficiently promoted transdermal delivery of human insulin in a pig ear skin ex vivo model [165].

Another interesting report by Vieira et al. concerns the characterization of fluorinated ILs as potential protein DTD facilitators [166]. In this recent study, 1:1 combination of the perfluorobutanesulfonate anion with 1-ethyl-3-methylimidazolium, 1-ethyl-3methylpyridinium, or cholinium cations (Figure 12) afforded ILs with high surface activity in aqueous media, i.e., SAILs. The self-assembling properties of these fluorinated SAILs were similar either in water or in buffered solutions of lysozyme, selected as the model cargo protein, which could be successfully encapsulated by the SAILs, except in the case of cholinium perfluorobutanesulfonate. Lysozyme release and activity studies showed the SAIL/protein systems to be reasonably stable for storage at $4{ }^{\circ} \mathrm{C}$ (no protein release up to $12 \mathrm{~h}$ with protein activity kept intact), whereas total protein release is observed after $12 \mathrm{~h}$ at $37^{\circ} \mathrm{C}[166]$.
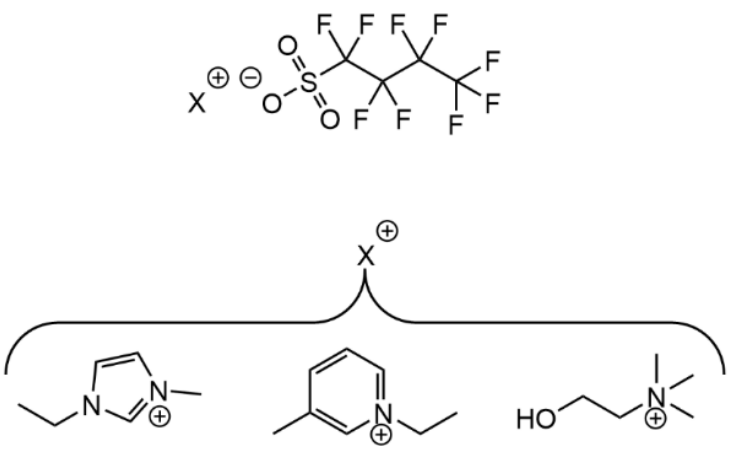

Figure 12. Perfluorobutanesulfonate-based ILs comprising the (from left to right) 1-methyl3-ethylimidazolium, 1-methyl-3-ethylpyridinium, and cholinium cations, as reported by Vieira et al. [166]. Adapted with permission from ref. [166]. Copyright 2020 MDPI. 
Like proteins, bioactive peptides hold great promise for therapeutic applications, with the further advantages of being more cost-effective and less prone to trigger immunoallergenic reactions. Interest is growing on topical delivery approaches for either antigenic peptides of interest for preventive vaccination, or host defense peptides (HDPs) encompassing antimicrobial and/or immunomodulatory effects [167]. Consequently, ILs are under the spotlight of the latest research on DTD of therapeutic peptides. For instance, Goto and co-workers developed hydrophobic fatty acid/amino ester-based ILs that were liquid at room temperature (i.e., RTILs) and fully miscible with common CPEs, such as isopropyl myristate (IPM) [168]. Formulations comprising 10\% wt of the RTILs in IPM showed lower cytotoxicity than the standard CPE sodium lauryl sulfate and being also able to better permeate a NSAID (ibuprofen) than the conventional CPE Transcutol ${ }^{\circledR}$. These formulations (especially the L-proline ethyl ester linoleate-based one), enhanced the percutaneous permeation of an antigenic peptide accross porcine skin [168]. The same authors have very recently used similar fatty acid-based ILs to formulate IL-in-oil nanodispersions that were optimized for higher physicochemical stability, as well as increased loading capacity and in vivo transdermal delivery of the anticancer nonapeptide leuprolide [169]. The nanodispersions showed no significant toxicity both in vitro and in vivo, and peptide transdermal delivery could be enhanced by as much as 65-fold compared with the aqueous delivery vehicle [169].

Tahara et al. have equally investigated fatty acid/choline-derived ILs as potential facilitators for the solubilization of an antigenic water-soluble peptide in an oil-based percutaneous permeation promoter [170]. The least cytotoxic IL cytotoxic, cholinium oleate, was dispersed with the peptide in the oil phase, and the resulting formulation showed a 28-fold enhancement of peptide transcutaneous permeation as compared to the aqueous vehicle. Moreover, this transdermal delivery formulation did not cause any detectable irritation on skin, and significantly suppressed tumor growth in vivo [170].

In regard to transdermal delivery of HDPs, latest efforts have focused on combination of antimicrobial HDPs with ILs possessing intrinsic antimicrobial activity, to afford new formulations whose percutaneous permeation and antimicrobial potency might be mutually enhanced. In this connection, Patel and co-workers mixed an HDP, melittin, with pyrrolidinium-based ILs, and the non-covalent HDP-IL conjugates thus formed displayed superior in vitro activity to those of their individual components against both Gram-negative (E. coli) and Gram-positive (S. aureus) bacteria, while showing no significant cytotoxicity [171]. The same authors further investigated the influence of the alkyl chain length of the pyrrolidinium-based ILs in both their individual antimicrobial potency, and synergistic action upon combination with melittin [172]. This study confirmed the potent synergic action against both $E$. coli and $S$. aureus when the HDP is combined with the ILs, and revealed a correlation between antimicrobial potency, which improved with the increase of the alkyl chain length in the IL [172]. Another example is the work reported by Gomes and co-workers [173]. In this study, coupling an antimicrobial methylimidazolium IL to the $N$-terminus of a collagenesis-inducing peptide with potent antibacterial and antibiofilm properties, delivered a covalent conjugate that retained the parent peptide's activity against multidrug-resistant clinical isolates of Gram-negative bacteria, and antibiofilm action on a resistant clinical isolate of Klebsiella pneumoniae, while exhibiting much improved stability towards tyrosinase-mediated modifications [173]. These abovementioned works are an overture for the potential held by IL-based strategies as tools to improve the properties of bioactive peptides.

\section{Will Ionic Liquids and Peptides Become Relevant Co-Players in the Future Management of Skin Infections?}

The encouraging findings highlighted in the last section, along with the latest reports on, e.g., (i) the fabrication of amphiphilic formulations comprising peptides and imidazolium- or betaninium-based ILs as new delivery nanoplatforms [174,175], and (ii) the relevance of developing cationic nanocarriers to overcome negatively-charged tissue barriers like the skin [176], hold great promise for the future management of skin 
infections, including CSSTI. Current progress in ILs-mediated percutaneous permeation of bioactive compounds, from small anti-inflammatory drugs to host defense peptides, and even lytic bacteriophages [177], together with the intrinsic antimicrobial action of many ILs, underline the capacity of ILs to become important players in innovative approaches to treat skin infections. Likewise, many HDPs combine antimicrobial, immunomodulatory and wound-healing properties, with a cationic amphiphilic structure often conveying cell-penetrating and/or self-assembling capacity. Hence, such HDPs will prospectively be useful both as carriers and as bioactive cargoes in transdermal delivery applications.

Effective management of infected wounds should ideally rely on topical formulations able to exert antimicrobial, anti-inflammatory, and healing effects from the outer to the innermost layers of the skin. ILs and HDPs have the potential to jointly contribute to such an achievement.

Author Contributions: Writing—original draft, A.G. and P.G.; writing—review and editing, C.T., L.A. and R.F.; funding acquisition, R.F., C.T. and P.G. All authors have read and agreed to the published version of the manuscript.

Funding: This work was funded by Fundação para a Ciência e Tecnologia/Ministério da Ciência, Tecnologia e Ensino Superior (FCT-MCTES, Portugal) through project PTDC/BTM-SAL/29786/2017.

Acknowledgments: Thanks are due to FCT-MCTES for funding through projects UIDB/50006/2020, and PTDC/BTM-SAL/29786/2017. A.G. thanks the M2B-PhD programme, FCT-MCTES, and the European Social Fund (ESF) for her Ph.D. grant ref. PD/BD/135073/2017, through Programa Operacional Capital Humano (POCH).

Conflicts of Interest: The authors declare no conflict of interest.

\section{References}

1. Benson, H.A.E.; Grice, J.E.; Mohammed, Y.; Namjoshi, S.; Roberts, M.S. Topical and Transdermal Drug Delivery: From Simple Potions to Smart Technologies. Curr. Drug Deliv. 2019, 16, 444-460. [CrossRef] [PubMed]

2. Calcutt, J.J.; Roberts, M.S.; Anissimov, Y.G. Modeling drug transport within the viable skin-A review. Expert Opin. Drug Metab. Toxicol. 2021, 17, 105-119. [CrossRef]

3. Kahraman, E.; Güngör, S.; Özsoy, Y. Potential enhancement and targeting strategies of polymeric and lipid-based nanocarriers in dermal drug delivery. Ther. Deliv. 2017, 8, 967-985. [CrossRef]

4. $\quad$ Pereira, R.; Silva, S.G.; Pinheiro, M.; Reis, S.; Vale, M.L. Current Status of Amino Acid-Based Permeation Enhancers in Transdermal Drug Delivery. Membranes 2021, 11, 343. [CrossRef]

5. Ramadon, D.; McCrudden, M.T.C.; Courtenay, A.J.; Donnelly, R.F. Enhancement strategies for transdermal drug delivery systems: Current trends and applications. Drug Deliv. Transl. Res. 2021, 1-34. [CrossRef]

6. Münch, S.; Wohlrab, J.; Neubert, R.H.H. Dermal and transdermal delivery of pharmaceutically relevant macromolecules. Eur. J. Pharm. Biopharm. 2017, 119, 235-242. [CrossRef]

7. Yu, Y.-Q.; Yang, X.; Wu, X.-F.; Fan, Y.-B. Enhancing Permeation of Drug Molecules across the Skin via Delivery in Nanocarriers: Novel Strategies for Effective Transdermal Applications. Front. Bioeng. Biotechnol. 2021, 9, 200. [CrossRef]

8. Municoy, S.; Alvarez Echazu, M.I.; Antezana, P.E.; Galdoporpora, J.M.; Olivetti, C.; Mebert, A.M.; Foglia, M.L.; Tuttolomondo, M.V.; Alvarez, G.S.; Hardy, J.G.; et al. Stimuli-Responsive Materials for Tissue Engineering and Drug Delivery. Int. J. Mol. Sci. 2020, 21, 4724. [CrossRef]

9. Kim, B.; Cho, H.-E.; Moon, S.H.; Ahn, H.-J.; Bae, S.; Cho, H.-D.; An, S. Transdermal delivery systems in cosmetics. Biomed. Dermatol. 2020, 4, 10. [CrossRef]

10. Gupta, R.; Dwadasi, B.S.; Rai, B.; Mitragotri, S. Effect of Chemical Permeation Enhancers on Skin Permeability: In silico screening using Molecular Dynamics simulations. Sci. Rep. 2019, 9, 1456. [CrossRef]

11. Hoang, T.P.; Ghori, M.U.; Conway, B.R. Topical Antiseptic Formulations for Skin and Soft Tissue Infections. Pharmaceutics 2021, 13, 558. [CrossRef]

12. Ferraz, R.; Teixeira, C.; Gomes, P.; Prudêncio, C. Chapter 16: Bioactivity of Ionic Liquids. In Ionic Liquid Devices; The Royal Society of Chemistry: London, UK, 2018; pp. 404-422.

13. Gamboa, A.; Schüßler, N.; Soto-Bustamante, E.; Romero-Hasler, P.; Meinel, L.; Morales, J.O. Delivery of ionizable hydrophilic drugs based on pharmaceutical formulation of ion pairs and ionic liquids. Eur. J. Pharm. Biopharm. 2020, 156, 203-218. [CrossRef] [PubMed]

14. Silva, A.T.; Teixeira, C.; Marques, E.F.; Prudêncio, C.; Gomes, P.; Ferraz, R. Surfing the Third Wave of Ionic Liquids: A Brief Review on the Role of Surface-Active Ionic Liquids in Drug Development and Delivery. ChemMedChem 2021, 16, 2604-2611. [CrossRef]

15. Tanner, E.E.L.; Curreri, A.M.; Balkaran, J.P.R.; Selig-Wober, N.C.; Yang, A.B.; Kendig, C.; Fluhr, M.P.; Kim, N.; Mitragotri, S. Design Principles of Ionic Liquids for Transdermal Drug Delivery. Adv. Mater. 2019, 31, 1901103. [CrossRef] [PubMed] 
16. Novickij, V.; Zinkevičienè, A.; Perminaitè, E.; Čèsna, R.; Lastauskienè, E.; Paškevičius, A.; Švedienè, J.; Markovskaja, S.; Novickij, J.; Girkontaitè, I. Non-invasive nanosecond electroporation for biocontrol of surface infections: An in vivo study. Sci. Rep. 2018, 8, 14516. [CrossRef]

17. Novickij, V.; Lastauskienè, E.; Staigvila, G.; Girkontaite, I.; Zinkevičienè, A.; Švedienė, J.; Paškevičius, A.; Markovskaja, S.; Novickij, J. Low concentrations of acetic and formic acids enhance the inactivation of Staphylococcus aureus and Pseudomonas aeruginosa with pulsed electric fields. BMC Microbiol. 2019, 19, 73. [CrossRef]

18. Das, B.; Shrirao, A.; Golberg, A.; Berthiaume, F.; Schloss, R.; Yarmush, M.L. Differential Cell Death and Regrowth of Dermal Fibroblasts and Keratinocytes After Application of Pulsed Electric Fields. Bioelectricity 2020, 2, 175-185. [CrossRef]

19. Bakshi, P.; Vora, D.; Hemmady, K.; Banga, A.K. Iontophoretic skin delivery systems: Success and failures. Int. J. Pharm. 2020, 586, 119584. [CrossRef] [PubMed]

20. Jiang, C.; Jiang, X.; Wang, X.; Shen, J.; Zhang, M.; Jiang, L.; Ma, R.; Gan, T.; Gong, Y.; Ye, J.; et al. Transdermal iontophoresis delivery system for terazosin hydrochloride: An in vitro and in vivo study. Drug Deliv. 2021, 28, 454-462. [CrossRef]

21. Iontophoresis of Treprostinil to Enhance Wound Healing in Diabetic Foot Skin Ulcers. Available online: https://www. smartpatients.com/trials/NCT03654989 (accessed on 10 October 2021).

22. Liao, A.-H.; Hung, C.-R.; Chen, H.-K.; Chiang, C.-P. Ultrasound-Mediated EGF-Coated-Microbubble Cavitation in Dressings for Wound-Healing Applications. Sci. Rep. 2018, 8, 8327. [CrossRef]

23. Chen, L.; Zheng, Q.; Chen, X.; Wang, J.; Wang, L. Low-frequency ultrasound enhances vascular endothelial growth factor expression, thereby promoting the wound healing in diabetic rats. Exp. Ther. Med. 2019, 18, 4040-4048. [CrossRef]

24. Halder, J.; Gupta, S.; Kumari, R.; Gupta, G.D.; Rai, V.K. Microneedle Array: Applications, Recent Advances, and Clinical Pertinence in Transdermal Drug Delivery. J. Pharm. Innov. 2021, 16, 558-565. [CrossRef]

25. Kirkby, M.; Hutton, A.R.J.; Donnelly, R.F. Microneedle Mediated Transdermal Delivery of Protein, Peptide and Antibody Based Therapeutics: Current Status and Future Considerations. Pharm. Res. 2020, 37, 117. [CrossRef]

26. Lim, S.H.; Tiew, W.J.; Zhang, J.; Ho, P.C.-L.; Kachouie, N.N.; Kang, L. Geometrical optimisation of a personalised microneedle eye patch for transdermal delivery of anti-wrinkle small peptide. Biofabrication 2020, 12, 035003. [CrossRef]

27. Barnum, L.; Samandari, M.; Schmidt, T.A.; Tamayol, A. Microneedle arrays for the treatment of chronic wounds. Expert Opin. Drug Deliv. 2020, 17, 1767-1780. [CrossRef]

28. Frydman, G.H.; Olaleye, D.; Annamalai, D.; Layne, K.; Yang, I.; Kaafarani, H.M.A.; Fox, J.G. Manuka honey microneedles for enhanced wound healing and the prevention and/or treatment of Methicillin-resistant Staphylococcus aureus (MRSA) surgical site infection. Sci. Rep. 2020, 10, 13229. [CrossRef]

29. Ibelli, T.; Templeton, S.; Levi-Polyachenko, N. Progress on utilizing hyperthermia for mitigating bacterial infections. Int. J. Hyperth. 2018, 34, 144-156. [CrossRef] [PubMed]

30. Mahmoud, N.N.; Alkilany, A.M.; Khalil, E.A.; Al-Bakri, A.G. Nano-Photothermal ablation effect of Hydrophilic and Hydrophobic Functionalized Gold Nanorods on Staphylococcus aureus and Propionibacterium acnes. Sci. Rep. 2018, 8, 6881. [CrossRef] [PubMed]

31. Alumutairi, L.; Yu, B.; Filka, M.; Nayfach, J.; Kim, M.-H. Mild magnetic nanoparticle hyperthermia enhances the susceptibility of Staphylococcus aureus biofilm to antibiotics. Int. J. Hyperth. 2020, 37, 66-75. [CrossRef]

32. Cheng, G.; Li, B. Nanoparticle-based photodynamic therapy: New trends in wound healing applications. Mater. Today Adv. 2020, 6, 100049. [CrossRef]

33. Kokolakis, G.; von Grawert, L.; Ulrich, M.; Lademann, J.; Zuberbier, T.; Hofmann, M.A. Wound Healing Process after Thermomechanical Skin Ablation. Lasers Surg. Med. 2020, 52, 730-734. [CrossRef] [PubMed]

34. Qiao, Y.; Ping, Y.; Zhang, H.; Zhou, B.; Liu, F.; Yu, Y.; Xie, T.; Li, W.; Zhong, D.; Zhang, Y.; et al. Laser-Activatable CuS Nanodots to Treat Multidrug-Resistant Bacteria and Release Copper Ion to Accelerate Healing of Infected Chronic Nonhealing Wounds. ACS Appl. Mater. Inter. 2019, 11, 3809-3822. [CrossRef] [PubMed]

35. Park, J.; Lee, H.; Lim, G.-S.; Kim, N.; Kim, D.; Kim, Y.-C. Enhanced Transdermal Drug Delivery by Sonophoresis and Simultaneous Application of Sonophoresis and Iontophoresis. AAPS PharmSciTech 2019, 20, 96. [CrossRef] [PubMed]

36. Parhi, R.; Mandru, A. Enhancement of skin permeability with thermal ablation techniques: Concept to commercial products. Drug Deliv. Transl. Res. 2021, 11, 817-841. [CrossRef]

37. Rai, V.K.; Mishra, N.; Yadav, K.S.; Yadav, N.P. Nanoemulsion as pharmaceutical carrier for dermal and transdermal drug delivery: Formulation development, stability issues, basic considerations and applications. J. Control. Release 2018, 270, 203-225. [CrossRef]

38. Shaker, D.S.; Ishak, R.A.H.; Ghoneim, A.; Elhuoni, M.A. Nanoemulsion: A Review on Mechanisms for the Transdermal Delivery of Hydrophobic and Hydrophilic Drugs. Sci. Pharm. 2019, 87, 17. [CrossRef]

39. Alghaith, A.F.; Alshehri, S.; Alhakamy, N.A.; Hosny, K.M. Development, optimization and characterization of nanoemulsion loaded with clove oil-naftifine antifungal for the management of tinea. Drug Deliv. 2021, 28, 343-356. [CrossRef]

40. Zhou, X.; Hao, Y.; Yuan, L.; Pradhan, S.; Shrestha, K.; Pradhan, O.; Liu, H.; Li, W. Nano-formulations for transdermal drug delivery: A review. Chin. Chem. Lett. 2018, 29, 1713-1724. [CrossRef]

41. Kassem, A.A.; Abd El-Alim, S.H. Vesicular Nanocarriers: A Potential Platform for Dermal and Transdermal Drug Delivery. In Nanopharmaceuticals: Principles and Applications; Yata, V.K., Ranjan, S., Dasgupta, N., Lichtfouse, E., Eds.; Springer International Publishing: Cham, Switzerland, 2021; Volume 2, pp. 155-209.

42. Jeong, W.Y.; Kwon, M.; Choi, H.E.; Kim, K.S. Recent advances in transdermal drug delivery systems: A review. Biomater. Res. 2021, 25, 24. [CrossRef] 
43. Patel, D.; Patel, B.; Thakkar, H. Lipid Based Nanocarriers: Promising Drug Delivery System for Topical Application. Eur. J. Lipid Sci. Technol. 2021, 123, 2000264. [CrossRef]

44. Yu, Z.; Meng, X.; Zhang, S.; Chen, Y.; Zhang, Z.; Zhang, Y. Recent Progress in Transdermal Nanocarriers and Their Surface Modifications. Molecules 2021, 26, 3093. [CrossRef] [PubMed]

45. Hua, S. Lipid-based nano-delivery systems for skin delivery of drugs and bioactives. Front. Pharmacol. 2015, 6, 219. [CrossRef]

46. Witika, B.A.; Mweetwa, L.L.; Tshiamo, K.O.; Edler, K.; Matafwali, S.K.; Ntemi, P.V.; Chikukwa, M.T.R.; Makoni, P.A. Vesicular drug delivery for the treatment of topical disorders: Current and future perspectives. J. Pharm. Pharmacol. 2021, 73, 1-15. [CrossRef] [PubMed]

47. Lai, F.; Caddeo, C.; Manca, M.L.; Manconi, M.; Sinico, C.; Fadda, A.M. What's new in the field of phospholipid vesicular nanocarriers for skin drug delivery. Int. J. Pharm. 2020, 583, 119398. [CrossRef]

48. Paiva-Santos, A.C.; Silva, A.L.; Guerra, C.; Peixoto, D.; Pereira-Silva, M.; Zeinali, M.; Mascarenhas-Melo, F.; Castro, R.; Veiga, F. Ethosomes as Nanocarriers for the Development of Skin Delivery Formulations. Pharm. Res. 2021, 38, 947-970. [CrossRef]

49. Opatha, S.A.; Titapiwatanakun, V.; Chutoprapat, R. Transfersomes: A Promising Nanoencapsulation Technique for Transdermal Drug Delivery. Pharmaceutics 2020, 12, 855. [CrossRef]

50. Durga, B.; Veera, L. Recent advances of non-ionic surfactant-based nano-vesicles (niosomes and proniosomes): A brief review of these in enhancing transdermal delivery of drug. Future J. Pharm. Sci. 2020, 6, 100. [CrossRef]

51. Kauslya, A.; Borawake, P.D.; Shinde, J.V.; Chavan, R. Niosomes: A Novel Carrier Drug Delivery System. J. Drug Deliv. Ther. 2021, 11, 162-170. [CrossRef]

52. Dawadi, S.; Katuwal, S.; Gupta, A.; Lamichhane, U.; Thapa, R.; Jaisi, S.; Lamichhane, G.; Bhattarai, D.P.; Parajuli, N. Current Research on Silver Nanoparticles: Synthesis, Characterization, and Applications. J. Nanomater. 2021, 2021, 6687290. [CrossRef]

53. Khalil, R.M.; Abdelbary, A.; Arini, S.K.E.; Basha, M.; El-Hashemy, H.A.; Farouk, F. Development of tizanidine loaded aspasomes as transdermal delivery system: Ex-vivo and in-vivo evaluation. J. Liposome Res. 2021, 31, 19-29. [CrossRef]

54. Zoabi, A.; Touitou, E.; Margulis, K. Recent Advances in Nanomaterials for Dermal and Transdermal Applications. J. Colloid Interface 2021, 5, 18. [CrossRef]

55. Miller, A.J.; Pearce, A.K.; Foster, J.C.; O’Reilly, R.K. Probing and Tuning the Permeability of Polymersomes. ACS Cent. Sci. 2021, 7, 30-38. [CrossRef]

56. Nigro, F.; Cerqueira Pinto, C.d.S.; dos Santos, E.P.; Mansur, C.R.E. Niosome-based hydrogel as a potential drug delivery system for topical and transdermal applications. Int. J. Polym. Mater. 2020, 1-18. [CrossRef]

57. Fu, X.; Shi, Y.; Wang, H.; Zhao, X.; Sun, Q.; Huang, Y.; Qi, T.; Lin, G. Ethosomal Gel for Improving Transdermal Delivery of Thymosin $\beta$-4. Int. J. Nanomed. 2019, 14, 9275-9284. [CrossRef]

58. Bhattacharya, S. Preparation and characterizations of glyceryl oleate ufasomes of terbinafine hydrochloride: A novel approach to trigger Candida albicans fungal infection. Future J. Pharm. Sci. 2021, 7, 3. [CrossRef]

59. Zhang, Y.; Liu, Y.; Liu, H.; Tang, W.H. Exosomes: Biogenesis, biologic function and clinical potential. Cell Biosci. 2019, 9, 19. [CrossRef]

60. Gu, T.-W.; Wang, M.-Z.; Niu, J.; Chu, Y.; Guo, K.-R.; Peng, L.-H. Outer membrane vesicles derived from E. coli as novel vehicles for transdermal and tumor targeting delivery. Nanoscale 2020, 12, 18965-18977. [CrossRef]

61. Liang, Y.; Duan, L.; Lu, J.; Xia, J. Engineering exosomes for targeted drug delivery. Theranostics 2021, 11, 3183-3195. [CrossRef]

62. Aslan, C.; Kiaie, S.H.; Zolbanin, N.M.; Lotfinejad, P.; Ramezani, R.; Kashanchi, F.; Jafari, R. Exosomes for mRNA delivery: A novel biotherapeutic strategy with hurdles and hope. BMC Biotechnol. 2021, 21, 20. [CrossRef]

63. Riau, A.K.; Ong, H.S.; Yam, G.H.F.; Mehta, J.S. Sustained Delivery System for Stem Cell-Derived Exosomes. Front. Pharmacol. 2019, 10, 1368. [CrossRef]

64. Xiong, M.; Zhang, Q.; Hu, W.; Zhao, C.; Lv, W.; Yi, Y.; Wang, Y.; Tang, H.; Wu, M.; Wu, Y. The novel mechanisms and applications of exosomes in dermatology and cutaneous medical aesthetics. Pharmacol. Res 2021, 166, 105490. [CrossRef]

65. Cho, B.S.; Lee, J.; Won, Y.; Duncan, D.I.; Jin, R.C.; Lee, J.; Kwon, H.H.; Park, G.-H.; Yang, S.H.; Park, B.C.; et al. Skin Brightening Efficacy of Exosomes Derived from Human Adipose Tissue-Derived Stem/Stromal Cells: A Prospective, Split-Face, Randomized Placebo-Controlled Study. Cosmetics 2020, 7, 90. [CrossRef]

66. Hu, P.; Yang, Q.; Wang, Q.; Shi, C.; Wang, D.; Armato, U.; Prà, I.D.; Chiarini, A. Mesenchymal stromal cells-exosomes: A promising cell-free therapeutic tool for wound healing and cutaneous regeneration. Burns Trauma 2019, 7, 38. [CrossRef] [PubMed]

67. Peng, L.-H.; Wang, M.-Z.; Chu, Y.; Zhang, L.; Niu, J.; Shao, H.-T.; Yuan, T.-J.; Jiang, Z.-H.; Gao, J.-Q.; Ning, X.-H. Engineering bacterial outer membrane vesicles as transdermal nanoplatforms for photo-TRAIL-programmed therapy against melanoma. Sci. Adv. 2020, 6, eaba2735. [CrossRef] [PubMed]

68. Kanwar, R.; Rathee, J.; Salunke, D.B.; Mehta, S.K. Green Nanotechnology-Driven Drug Delivery Assemblies. ACS Omega 2019, 4 , 8804-8815. [CrossRef] [PubMed]

69. Khan, I.; Saeed, K.; Khan, I. Nanoparticles: Properties, applications and toxicities. Arab. J. Chem. 2019, 12, 908-931. [CrossRef]

70. Shirodkar, R.K.; Kumar, L.; Mutalik, S.; Lewis, S. Solid Lipid Nanoparticles and Nanostructured Lipid Carriers: Emerging Lipid Based Drug Delivery Systems. Pharm. Chem. J. 2019, 53, 440-453. [CrossRef]

71. Dhiman, N.; Awasthi, R.; Sharma, B.; Kharkwal, H.; Kulkarni, G.T. Lipid Nanoparticles as Carriers for Bioactive Delivery. Front. Chem. 2021, 9, 580118. [CrossRef] 
72. Montoto, S.; Muraca, G.; Ruiz, M.E. Solid Lipid Nanoparticles for Drug Delivery: Pharmacological and Biopharmaceutical Aspects. Front. Mol. Biosci. 2020, 7, 319. [CrossRef]

73. Souto, E.B.; Baldim, I.; Oliveira, W.P.; Rao, R.; Yadav, N.; Gama, F.M.; Mahant, S. SLN and NLC for topical, dermal, and transdermal drug delivery. Expert. Opin. Drug Deliv. 2020, 17, 357-377. [CrossRef]

74. Khater, D.; Nsairat, H.; Odeh, F.; Saleh, M.; Jaber, A.; Alshaer, W.; Al Bawab, A.; Mubarak, M.S. Design, Preparation, and Characterization of Effective Dermal and Transdermal Lipid Nanoparticles: A Review. Cosmetics 2021, 8, 39. [CrossRef]

75. Wang, W.; Lu, K.-j.; Yu, C.-h.; Huang, Q.-1.; Du, Y.-Z. Nano-drug delivery systems in wound treatment and skin regeneration. J. Nanobiotechnol. 2019, 17, 82. [CrossRef] [PubMed]

76. Matei, A.-M.; Caruntu, C.; Tampa, M.; Georgescu, S.R.; Matei, C.; Constantin, M.M.; Constantin, T.V.; Calina, D.; Ciubotaru, D.A.; Badarau, I.A.; et al. Applications of Nanosized-Lipid-Based Drug Delivery Systems in Wound Care. Appl. Sci. 2021, 11, 4915. [CrossRef]

77. De Souza, M.L.; dos Santos, W.M.; de Sousa, A.L.M.D.; Sales, V.d.A.W.; Nobrega, F.P.; de Oliveira, M.V.G.; Rolim-Neto, P.J. Lipid Nanoparticles as a Skin Wound Healing Drug Delivery System: Discoveries and Advances. Curr. Pharm. Des. 2020, 26, 4536-4550. [CrossRef] [PubMed]

78. Gad, H.A.; Abd El-Rahman, F.A.A.; Hamdy, G.M. Chamomile oil loaded solid lipid nanoparticles: A naturally formulated remedy to enhance the wound healing. J. Drug Deliv. Sci. Technol. 2019, 50, 329-338. [CrossRef]

79. Saporito, F.; Sandri, G.; Bonferoni, M.C.; Rossi, S.; Boselli, C.; Icaro Cornaglia, A.; Mannucci, B.; Grisoli, P.; Vigani, B.; Ferrari, F. Essential oil-loaded lipid nanoparticles for wound healing. Int. J. Nanomed. 2017, 13, 175-186. [CrossRef] [PubMed]

80. Liakopoulou, A.; Mourelatou, E.; Hatziantoniou, S. Exploitation of traditional healing properties, using the nanotechnology's advantages: The case of curcumin. Toxicol. Rep. 2021, 8, 1143-1155. [CrossRef] [PubMed]

81. Thorn, C.R.; Thomas, N.; Boyd, B.J.; Prestidge, C.A. Nano-fats for bugs: The benefits of lipid nanoparticles for antimicrobial therapy. Drug Deliv. Transl. Res. 2021, 11, 1598-1624. [CrossRef]

82. Pinilla, C.M.; Lopes, N.A.; Brandelli, A. Lipid-Based Nanostructures for the Delivery of Natural Antimicrobials. Molecules 2021, 26, 3587. [CrossRef]

83. Araujo, V.H.S.; Delello Di Filippo, L.; Duarte, J.L.; Spósito, L.; Camargo, B.A.F.d.; da Silva, P.B.; Chorilli, M. Exploiting solid lipid nanoparticles and nanostructured lipid carriers for drug delivery against cutaneous fungal infections. Crit. Rev. Microbiol. 2021, 47, 79-90. [CrossRef]

84. Arana, L.; Gallego, L.; Alkorta, I. Incorporation of Antibiotics into Solid Lipid Nanoparticles: A Promising Approach to Reduce Antibiotic Resistance Emergence. Nanomaterials 2021, 11, 1251. [CrossRef] [PubMed]

85. Dos Santos Ramos, M.A.; de Toledo, L.G.; Spósito, L.; Marena, G.D.; de Lima, L.C.; Fortunato, G.C.; Araújo, V.H.S.; Bauab, T.M.; Chorilli, M. Nanotechnology-based lipid systems applied to resistant bacterial control: A review of their use in the past two decades. Int. J. Pharm. 2021, 603, 120706. [CrossRef] [PubMed]

86. Mamun, M.M.; Sorinolu, A.J.; Munir, M.; Vejerano, E.P. Nanoantibiotics: Functions and Properties at the Nanoscale to Combat Antibiotic Resistance. Front. Chem. 2021, 9, 348. [CrossRef] [PubMed]

87. Sguizzato, M.; Esposito, E.; Cortesi, R. Lipid-Based Nanosystems as a Tool to Overcome Skin Barrier. Int. J. Mol. Sci. 2021, 22, 8319. [CrossRef]

88. Walduck, A.; Sangwan, P.; Vo, Q.A.; Ratcliffe, J.; White, J.; Muir, B.W.; Tran, N. Treatment of Staphylococcus aureus skin infection in vivo using rifampicin loaded lipid nanoparticles. RSC Adv. 2020, 10, 33608-33619. [CrossRef]

89. Mittal, P.; Saharan, A.; Verma, R.; Altalbawy, F.M.A.; Alfaidi, M.A.; Batiha, G.E.-S.; Akter, W.; Gautam, R.K.; Uddin, M.S.; Rahman, M.S. Dendrimers: A New Race of Pharmaceutical Nanocarriers. Biomed Res. Int. 2021, 2021, 8844030. [CrossRef]

90. Nikzamir, M.; Hanifehpour, Y.; Akbarzadeh, A.; Panahi, Y. Applications of Dendrimers in Nanomedicine and Drug Delivery: A Review. J. Inorg. Organomet. Polym. Mater. 2021, 31, 2246-2261. [CrossRef]

91. Santos, A.; Veiga, F.; Figueiras, A. Dendrimers as Pharmaceutical Excipients: Synthesis, Properties, Toxicity and Biomedical Applications. Materials 2020, 13, 65. [CrossRef]

92. Kirkby, M.; Sabri, A.B.; Scurr, D.J.; Moss, G.P. Dendrimer-mediated permeation enhancement of chlorhexidine digluconate: Determination of in vitro skin permeability and visualisation of dermal distribution. Eur. J. Pharm. Biopharm. 2021, 159, 77-87. [CrossRef]

93. Gökçe, B.B.; Boran, T.; Emlik Çalık, F.; Özhan, G.; Sanyal, R.; Güngör, S. Dermal delivery and follicular targeting of adapalene using PAMAM dendrimers. Drug Deliv. Transl. Res. 2021, 11, 626-646. [CrossRef]

94. Sung, Y.K.; Kim, S.W. Recent advances in polymeric drug delivery systems. Biomater. Res. 2020, 24, 12. [CrossRef]

95. Van Gheluwe, L.; Chourpa, I.; Gaigne, C.; Munnier, E. Polymer-Based Smart Drug Delivery Systems for Skin Application and Demonstration of Stimuli-Responsiveness. Polymers 2021, 13, 1285. [CrossRef]

96. Praveen, A.; Aqil, M. Transdermal Delivery of Chitosan-Based Systems. In Functional Chitosan: Drug Delivery and Biomedical Applications; Jana, S., Jana, S., Eds.; Springer: Singapore, 2019; pp. 75-106.

97. Bagheri, F.; Darakhshan, S.; Mazloomi, S.; Shiri Varnamkhasti, B.; Tahvilian, R. Dual loading of Nigella sativa oil-atorvastatin in chitosan-carboxymethyl cellulose nanogel as a transdermal delivery system. Drug Dev. Ind. Pharm. 2021, 47, 569-578. [CrossRef] [PubMed] 
98. Sun, L.; Li, J.; Gao, W.; Shi, M.; Tang, F.; Fu, X.; Chen, X. Coaxial nanofibrous scaffolds mimicking the extracellular matrix transition in the wound healing process promoting skin regeneration through enhancing immunomodulation. J. Mater. Chem. $B$ 2021, 9, 1395-1405. [CrossRef] [PubMed]

99. Paul, W.; Sharma, C.P. 13-Inorganic nanoparticles for targeted drug delivery. In Biointegration of Medical Implant Materials, 2nd ed.; Sharma, C.P., Ed.; Woodhead Publishing: Sawston, UK, 2020; pp. 333-373.

100. Shi, Z.; Zhou, Y.; Fan, T.; Lin, Y.; Zhang, H.; Mei, L. Inorganic nano-carriers based smart drug delivery systems for tumor therapy. Smart Mater. Res. 2020, 1, 32-47. [CrossRef]

101. Zhou, H.; Ge, J.; Miao, Q.; Zhu, R.; Wen, L.; Zeng, J.; Gao, M. Biodegradable Inorganic Nanoparticles for Cancer Theranostics: Insights into the Degradation Behavior. Bioconjug. Chem. 2020, 31, 315-331. [CrossRef]

102. Gulin-Sarfraz, T.; Kalantzopoulos, G.N.; Kvalvåg Pettersen, M.; Wold Åsli, A.; Tho, I.; Axelsson, L.; Sarfraz, J. Inorganic Nanocarriers for Encapsulation of Natural Antimicrobial Compounds for Potential Food Packaging Application: A Comparative Study. Nanomaterials 2021, 11, 379. [CrossRef] [PubMed]

103. Raviraj, V.; Pham, B.T.T.; Kim, B.J.; Pham, N.T.H.; Kok, L.F.; Painter, N.; Delic, N.C.; Jones, S.K.; Hawkett, B.S.; Lyons, J.G. Non-invasive transdermal delivery of chemotherapeutic molecules in vivo using superparamagnetic iron oxide nanoparticles. Cancer Nanotechnol. 2021, 12, 6. [CrossRef]

104. Spirescu, V.A.; Chircov, C.; Grumezescu, A.M.; Vasile, B.S.; Andronescu, E. Inorganic Nanoparticles and Composite Films for Antimicrobial Therapies. Int. J. Mol. Sci. 2021, 22, 4595. [CrossRef]

105. Bruna, T.; Maldonado-Bravo, F.; Jara, P.; Caro, N. Silver Nanoparticles and Their Antibacterial Applications. Int. J. Mol. Sci. 2021, 22, 7202. [CrossRef]

106. Mussin, J.; Robles-Botero, V.; Casañas-Pimentel, R.; Rojas, F.; Angiolella, L.; San Martín-Martínez, E.; Giusiano, G. Antimicrobial and cytotoxic activity of green synthesis silver nanoparticles targeting skin and soft tissue infectious agents. Sci. Rep. 2021, 11, 14566. [CrossRef]

107. Gautam, R.; Yang, S.; Maharjan, A.; Jo, J.; Acharya, M.; Heo, Y.; Kim, C. Prediction of Skin Sensitization Potential of Silver and Zinc Oxide Nanoparticles Through the Human Cell Line Activation Test. Front. Toxicol. 2021, 3, 26. [CrossRef]

108. Silva, F.A.L.S.; Costa-Almeida, R.; Timochenco, L.; Amaral, S.I.; Pinto, S.; Gonçalves, I.C.; Fernandes, J.R.; Magalhães, F.D.; Sarmento, B.; Pinto, A.M. Graphene Oxide Topical Administration: Skin Permeability Studies. Materials 2021, 14, 2810. [CrossRef] [PubMed]

109. Soliman, M.; Sadek, A.A.; Abdelhamid, H.N.; Hussein, K. Graphene oxide-cellulose nanocomposite accelerates skin wound healing. Vet. Sci. Res. J. 2021, 137, 262-273. [CrossRef] [PubMed]

110. Mei, D.; Guo, X.; Wang, Y.; Huang, X.; Guo, L.; Zou, P.; Ge, D.; Wang, X.; Lee, W.; Sun, T.; et al. PEGylated Graphene Oxide Carried $\mathrm{OH}-\mathrm{CATH} 30$ to Accelerate the Healing of Infected Skin Wounds. Int. J. Nanomed. 2021, 16, 4769-4780. [CrossRef] [PubMed]

111. Pormohammad, A.; Monych, N.K.; Ghosh, S.; Turner, D.L.; Turner, R.J. Nanomaterials in Wound Healing and Infection Control. Antibiotics 2021, 10, 473. [CrossRef] [PubMed]

112. Zhang, X.; Chen, G.; Liu, Y.; Sun, L.; Sun, L.; Zhao, Y. Black Phosphorus-Loaded Separable Microneedles as Responsive Oxygen Delivery Carriers for Wound Healing. ACS Nano 2020, 14, 5901-5908. [CrossRef] [PubMed]

113. Sully, R.E.; Garelick, H.; Loizidou, E.Z.; Podoleanu, A.G.; Gubala, V. Nanoparticle-infused-biodegradable-microneedles as drug-delivery systems: Preparation and characterisation. Adv. Mater. 2021, 2, 5432-5442. [CrossRef]

114. Elahpour, N.; Pahlevanzadeh, F.; Kharaziha, M.; Bakhsheshi-Rad, H.R.; Ramakrishna, S.; Berto, F. 3D printed microneedles for transdermal drug delivery: A brief review of two decades. Int. J. Pharm. 2021, 597, 120301. [CrossRef]

115. Dragicevic, N.; Atkinson, J.P.; Maibach, H.I. Chemical Penetration Enhancers: Classification and Mode of Action. In Percutaneous Penetration Enhancers Chemical Methods in Penetration Enhancement: Modification of the Stratum Corneum; Dragicevic, N., Maibach, H.I., Eds.; Springer: Berlin/Heidelberg, Germany, 2015; pp. 11-27.

116. Haque, T.; Talukder, M.M.U. Chemical Enhancer: A Simplistic Way to Modulate Barrier Function of the Stratum Corneum. Adv. Pharm. Bull. 2018, 8, 169-179. [CrossRef]

117. Gupta, R.; Badhe, Y.; Rai, B.; Mitragotri, S. Molecular mechanism of the skin permeation enhancing effect of ethanol: A molecular dynamics study. RSC Adv. 2020, 10, 12234-12248. [CrossRef]

118. Hasan, A.; Farooqui, H. A Review on Role of Essential Oil as Penetration Enhancer in Transdermal Drug Delivery System. Syst. Rev. Pharm. 2021, 12, 439-444.

119. Vasyuchenko, E.P.; Orekhov, P.S.; Armeev, G.A.; Bozdaganyan, M.E. CPE-DB: An Open Database of Chemical Penetration Enhancers. Pharmaceutics 2021, 13, 66. [CrossRef]

120. Welton, T. Ionic liquids: A brief history. Biophys. Rev. 2018, 10, 691-706. [CrossRef] [PubMed]

121. Rogers, R.D.; Gurau, G. Is "choline and geranate" an ionic liquid or deep eutectic solvent system? Proc. Natl. Acad. Sci. USA 2018, 115, E10999. [CrossRef]

122. Tullo, A.H. The Time Is Now for Ionic Liquids. Available online: https://cen.acs.org/materials/ionic-liquids/time-ionic-liquids/ 98/i5 (accessed on 15 September 2021).

123. Lei, Z.; Chen, B.; Koo, Y.M.; MacFarlane, D.R. Introduction: Ionic Liquids. Chem. Rev. 2017, 117, 6633-6635. [CrossRef] [PubMed]

124. Pedro, S.N.; Freire, C.S.R.; Silvestre, A.J.D.; Freire, M.G. Ionic Liquids in Drug Delivery. Encyclopedia 2021, 1, 27. [CrossRef]

125. Pedro, S.N.; Freire, C.S.R.; Silvestre, A.J.D.; Freire, M.G. The Role of Ionic Liquids in the Pharmaceutical Field: An Overview of Relevant Applications. Int. J. Mol. Sci. 2020, 21, 8298. [CrossRef] 
126. Silva, A.T.; Lobo, L.; Oliveira, I.S.; Gomes, J.; Teixeira, C.; Nogueira, F.; Marques, E.F.; Ferraz, R.; Gomes, P. Building on Surface-Active Ionic Liquids for the Rescuing of the Antimalarial Drug Chloroquine. Int. J. Mol. Sci. 2020, 21, 5334. [CrossRef]

127. Kumar, H.; Kaur, G. Scrutinizing Self-Assembly, Surface Activity and Aggregation Behavior of Mixtures of Imidazolium Based Ionic Liquids and Surfactants: A Comprehensive Review. Front. Chem. 2021, 9, 667941. [CrossRef] [PubMed]

128. Ana Rita, D.; João, C.-R.; Cátia, T.; Cristina, P.; Paula, G.; Ricardo, F. Ionic Liquids for Topical Delivery in Cancer. Curr. Med. Chem. 2019, 26, 7520-7532. [CrossRef]

129. Sidat, Z.; Marimuthu, T.; Kumar, P.; du Toit, L.C.; Kondiah, P.P.D.; Choonara, Y.E.; Pillay, V. Ionic Liquids as Potential and Synergistic Permeation Enhancers for Transdermal Drug Delivery. Pharmaceutics 2019, 11, 96. [CrossRef] [PubMed]

130. Md Moshikur, R.; Chowdhury, M.R.; Moniruzzaman, M.; Goto, M. Biocompatible ionic liquids and their applications in pharmaceutics. Green Chem. 2020, 22, 8116-8139. [CrossRef]

131. Qi, Q.M.; Duffy, M.; Curreri, A.M.; Balkaran, J.P.R.; Tanner, E.E.L.; Mitragotri, S. Comparison of Ionic Liquids and Chemical Permeation Enhancers for Transdermal Drug Delivery. Adv. Funct. Mater. 2020, 30, 2004257. [CrossRef]

132. Qi, Q.M.; Mitragotri, S. Mechanistic study of transdermal delivery of macromolecules assisted by ionic liquids. J. Control. Release 2019, 311-312, 162-169. [CrossRef] [PubMed]

133. Wu, H.; Deng, Z.; Zhou, B.; Qi, M.; Hong, M.; Ren, G. Improved transdermal permeability of ibuprofen by ionic liquid technology: Correlation between counterion structure and the physicochemical and biological properties. J. Mol. Liq. 2019, 283, 399-409. [CrossRef]

134. Yuan, J.; Wu, J.; Yin, T. Solubility and permeation enhancement of poor soluble drug by cholinium-amino acid based ionic liquids. J. Drug Deliv. Sci. Technol. 2020, 60, 102037. [CrossRef]

135. Chantereau, G.; Sharma, M.; Abednejad, A.; Neves, B.M.; Sèbe, G.; Coma, V.; Freire, M.G.; Freire, C.S.R.; Silvestre, A.J.D. Design of Nonsteroidal Anti-Inflammatory Drug-Based Ionic Liquids with Improved Water Solubility and Drug Delivery. ACS Sustain. Chem. Eng. 2019, 7, 14126-14134. [CrossRef]

136. Suksaeree, J.; Maneewattanapinyo, P. Ionic Liquid Drug-based Polymeric Matrices for Transdermal Delivery of Lidocaine and Diclofenac. J. Polym. Environ. 2020, 28, 2771-2779. [CrossRef]

137. Da Silva, C.C.P.; Dayo Owoyemi, B.C.; Alvarenga, B.R., Jr.; Alvarez, N.; Ellena, J.; Carneiro, R.L. Synthesis and solid-state characterization of diclofenac imidazolium monohydrate: An imidazolium pharmaceutical ionic liquid. CrystEngComm 2020, 22, 5345-5354. [CrossRef]

138. Maneewattanapinyo, P.; Yeesamun, A.; Watthana, F.; Panrat, K.; Pichayakorn, W.; Suksaeree, J. Controlled Release of LidocaineDiclofenac Ionic Liquid Drug from Freeze-Thawed Gelatin/Poly(Vinyl Alcohol) Transdermal Patches. AAPS PharmSciTech 2019, 20, 322. [CrossRef] [PubMed]

139. Abednejad, A.; Ghaee, A.; Morais, E.S.; Sharma, M.; Neves, B.M.; Freire, M.G.; Nourmohammadi, J.; Mehrizi, A.A. Polyvinylidene fluoride-Hyaluronic acid wound dressing comprised of ionic liquids for controlled drug delivery and dual therapeutic behavior. Acta Biomater. 2019, 100, 142-157. [CrossRef] [PubMed]

140. Zheng, L.; Zhao, Z.; Yang, Y.; Li, Y.; Wang, C. Novel skin permeation enhancers based on amino acid ester ionic liquid: Design and permeation mechanism. Int. J. Pharm. 2020, 576, 119031. [CrossRef] [PubMed]

141. Lu, B.; Yi, M.; Hu, S.; Wu, D.; Zhu, Z.; Wu, C.; Wang, Z.; Li, Y.; Zhang, J. Taurine-Based Ionic Liquids for Transdermal Protein Delivery and Enhanced Anticancer Activity. ACS Sustain. Chem. Eng. 2021, 9, 5991-6000. [CrossRef]

142. Wu, H.; Fang, F.; Zheng, L.; Ji, W.; Qi, M.; Hong, M.; Ren, G. Ionic liquid form of donepezil: Preparation, characterization and formulation development. J. Mol. Liq. 2020, 300, 112308. [CrossRef]

143. Hattori, T.; Tagawa, H.; Inai, M.; Kan, T.; Kimura, S.-i.; Itai, S.; Mitragotri, S.; Iwao, Y. Transdermal delivery of nobiletin using ionic liquids. Sci. Rep. 2019, 9, 20191. [CrossRef]

144. Zhou, Z.; Liu, C.; Wan, X.; Fang, L. Development of a w/o emulsion using ionic liquid strategy for transdermal delivery of anti-aging component $\alpha$-lipoic acid: Mechanism of different ionic liquids on skin retention and efficacy evaluation. Eur. J. Pharm. Sci. 2020, 141, 105042. [CrossRef]

145. Caparica, R.; Júlio, A.; Fernandes, F.; Araújo, M.E.M.; Costa, J.G.; Santos de Almeida, T. Upgrading the Topical Delivery of Poorly Soluble Drugs Using Ionic Liquids as a Versatile Tool. Int. J. Mol. Sci. 2021, 22, 4338. [CrossRef]

146. Chantereau, G.; Sharma, M.; Abednejad, A.; Vilela, C.; Costa, E.M.; Veiga, M.; Antunes, F.; Pintado, M.M.; Sèbe, G.; Coma, V.; et al. Bacterial nanocellulose membranes loaded with vitamin B-based ionic liquids for dermal care applications. J. Mol. Liq. 2020, 302, 112547. [CrossRef]

147. Islam, M.R.; Chowdhury, M.R.; Wakabayashi, R.; Kamiya, N.; Moniruzzaman, M.; Goto, M. Ionic Liquid-In-Oil Microemulsions Prepared with Biocompatible Choline Carboxylic Acids for Improving the Transdermal Delivery of a Sparingly Soluble Drug. Pharmaceutics 2020, 12, 392. [CrossRef]

148. Islam, M.R.; Chowdhury, M.R.; Wakabayashi, R.; Tahara, Y.; Kamiya, N.; Moniruzzaman, M.; Goto, M. Choline and amino acid based biocompatible ionic liquid mediated transdermal delivery of the sparingly soluble drug acyclovir. Int. J. Pharm. 2020, 582, 119335. [CrossRef] [PubMed]

149. Bakshi, K.; Mitra, S.; Sharma, V.K.; Jayadev, M.S.K.; Sakai, V.G.; Mukhopadhyay, R.; Gupta, A.; Ghosh, S.K. Imidazolium-based ionic liquids cause mammalian cell death due to modulated structures and dynamics of cellular membrane. Biochim. Biophys. Acta Biomembr. 2020, 1862, 183103. [CrossRef] [PubMed]

150. Poh, Y.; Ng, S.; Ho, K. Formulation and characterisation of 1-ethyl-3-methylimidazolium acetate-in-oil microemulsions as the potential vehicle for drug delivery across the skin barrier. J. Mol. Liq. 2019, 273, 339-345. [CrossRef] 
151. Takahashi, C.; Hattori, Y.; Yagi, S.; Murai, T.; Takai, C.; Ogawa, N.; Tanemura, M.; Fuji, M.; Kawashima, Y.; Yamamoto, H. Optimization of ionic liquid-incorporated PLGA nanoparticles for treatment of biofilm infections. Mater. Sci. Eng. C 2019, 97, 78-83. [CrossRef] [PubMed]

152. Greene, J.R.; Merrett, K.L.; Heyert, A.J.; Simmons, L.F.; Migliori, C.M.; Vogt, K.C.; Castro, R.S.; Phillips, P.D.; Baker, J.L.; Lindberg, G.E.; et al. Scope and efficacy of the broad-spectrum topical antiseptic choline geranate. PLoS ONE 2019, 14, e0222211. [CrossRef]

153. Wu, X.; Yu, Q.; Wu, J.; Li, T.; Ding, N.; Wu, W.; Lu, Y.; Zhu, Q.; Chen, Z.; Qi, J. Ionic liquids containing ketoconazole improving topical treatment of T. Interdigitale infection by synergistic action. Int. J. Pharm. 2020, 589, 119842. [CrossRef] [PubMed]

154. Zhang, Y.; Cao, Y.; Meng, X.; Li, C.; Wang, H.; Zhang, S. Enhancement of transdermal delivery of artemisinin using microemulsion vehicle based on ionic liquid and lidocaine ibuprofen. Colloids Surf. B 2020, 189, 110886. [CrossRef]

155. Zhang, T.; Sun, B.; Guo, J.; Wang, M.; Cui, H.; Mao, H.; Wang, B.; Yan, F. Active pharmaceutical ingredient poly(ionic liquid)-based microneedles for the treatment of skin acne infection. Acta Biomater. 2020, 115, 136-147. [CrossRef]

156. Bento, C.M.; Gomes, M.S.; Silva, T. Looking beyond Typical Treatments for Atypical Mycobacteria. Antibiotics 2020, 9, 18. [CrossRef]

157. Torres-Vanegas, J.D.; Cruz, J.C.; Reyes, L.H. Delivery Systems for Nucleic Acids and Proteins: Barriers, Cell Capture Pathways and Nanocarriers. Pharmaceutics 2021, 13, 428. [CrossRef]

158. Long, L.-y.; Zhang, J.; Yang, Z.; Guo, Y.; Hu, X.; Wang, Y. Transdermal delivery of peptide and protein drugs: Strategies, advantages and disadvantages. J. Drug Deliv. Sci. Technol. 2020, 60, 102007. [CrossRef]

159. Wu, X.; Zhang, H.; He, S.; Yu, Q.; Lu, Y.; Wu, W.; Ding, N.; Zhu, Q.; Chen, Z.; Ma, Y.; et al. Improving dermal delivery of hyaluronic acid by ionic liquids for attenuating skin dehydration. Int. J. Biol. Macromol. 2020, 150, 528-535. [CrossRef] [PubMed]

160. Mandal, A.; Kumbhojkar, N.; Reilly, C.; Dharamdasani, V.; Ukidve, A.; Ingber Donald, E.; Mitragotri, S. Treatment of psoriasis with NFKBIZ siRNA using topical ionic liquid formulations. Sci. Adv. 2020, 6, eabb6049. [CrossRef]

161. Tanner, E.E.L.; Wiraja, C.; Curreri, C.A.; Xu, C.; Mitragotri, S. Stabilization and Topical Skin Delivery of Framework Nucleic Acids using Ionic Liquids. Adv. Ther. 2020, 3, 2000041. [CrossRef]

162. Usmani, S.S.; Bedi, G.; Samuel, J.S.; Singh, S.; Kalra, S.; Kumar, P.; Ahuja, A.A.; Sharma, M.; Gautam, A.; Raghava, G.P.S. THPdb: Database of FDA-approved peptide and protein therapeutics. PLoS ONE 2017, 12, e0181748. [CrossRef]

163. Verma, S.; Goand, U.K.; Husain, A.; Katekar, R.A.; Garg, R.; Gayen, J.R. Challenges of peptide and protein drug delivery by oral route: Current strategies to improve the bioavailability. Drug Dev. Res. 2021. ahead-of-print. [CrossRef]

164. Vaidya, A.; Mitragotri, S. Ionic liquid-mediated delivery of insulin to buccal mucosa. J. Control. Release 2020, 327, 26-34. [CrossRef]

165. Jorge, L.R.; Harada, L.K.; Silva, E.C.; Campos, W.F.; Moreli, F.C.; Shimamoto, G.; Pereira, J.F.B.; Oliveira, J.M.; Tubino, M.; Vila, M.M.D.C.; et al. Non-invasive Transdermal Delivery of Human Insulin Using Ionic Liquids: In vitro Studies. Front. Pharmacol. 2020, 11, 243. [CrossRef]

166. Vieira, N.S.M.; Castro, P.J.; Marques, D.F.; Araújo, J.M.M.; Pereiro, A.B. Tailor-Made Fluorinated Ionic Liquids for Protein Delivery. Nanomaterials 2020, 10, 1594. [CrossRef] [PubMed]

167. Costa, F.; Teixeira, C.; Gomes, P.; Martins, M.C.L. Clinical Application of AMPs. In Antimicrobial Peptides: Basics for Clinical Application; Matsuzaki, K., Ed.; Springer: Singapore, 2019; pp. 281-298.

168. Md Moshikur, R.; Chowdhury, M.R.; Fujisawa, H.; Wakabayashi, R.; Moniruzzaman, M.; Goto, M. Design and Characterization of Fatty Acid-Based Amino Acid Ester as a New "Green" Hydrophobic Ionic Liquid for Drug Delivery. ACS Sustain. Chem. Eng. 2020, 8, 13660-13671. [CrossRef]

169. Uddin, S.; Islam, M.R.; Chowdhury, M.R.; Wakabayashi, R.; Kamiya, N.; Moniruzzaman, M.; Goto, M. Lipid-Based Ionic-LiquidMediated Nanodispersions as Biocompatible Carriers for the Enhanced Transdermal Delivery of a Peptide Drug. ACS Appl. Bio Mater. 2021, 4, 6256-6267. [CrossRef]

170. Tahara, Y.; Morita, K.; Wakabayashi, R.; Kamiya, N.; Goto, M. Biocompatible Ionic Liquid Enhances Transdermal Antigen Peptide Delivery and Preventive Vaccination Effect. Mol. Pharm. 2020, 17, 3845-3856. [CrossRef] [PubMed]

171. Saraswat, J.; Wani, F.A.; Dar, K.I.; Rizvi, M.M.A.; Patel, R. Noncovalent Conjugates of Ionic Liquid with Antibacterial Peptide Melittin: An Efficient Combination against Bacterial Cells. ACS Omega 2020, 5, 6376-6388. [CrossRef] [PubMed]

172. Saraswat, J.; Aldahmash, B.; AlOmar, S.Y.; Imtiyaz, K.; Rizvi, M.M.A.; Patel, R. Synergistic antimicrobial activity of N-methyl substituted pyrrolidinium-based ionic liquids and melittin against Gram-positive and Gram-negative bacteria. Appl. Microbiol. Biotechnol. 2020, 104, 10465-10479. [CrossRef]

173. Gomes, A.; Bessa, L.J.; Correia, P.; Fernandes, I.; Ferraz, R.; Gameiro, P.; Teixeira, C.; Gomes, P. “Clicking” an Ionic Liquid to a Potent Antimicrobial Peptide: On the Route towards Improved Stability. Int. J. Mol. Sci. 2020, 21, 6174. [CrossRef] [PubMed]

174. Daso, R.E.; Osborn, L.J.; Thomas, M.F.; Banerjee, I.A. Development of Nanoscale Hybrids from Ionic Liquid-Peptide Amphiphile Assemblies as New Functional Materials. ACS Omega 2020, 5, 14543-14554. [CrossRef]

175. Whalen, M.S.; Daso, R.E.; Thomas, M.F.; Banerjee, I.A. Interactions of betainium and imidazolium-based ionic liquids with peptide amphiphiles and their implications in the formation of nanohybrid composite gels. J. Sol-Gel Sci. Technol. 2021, 97, 488-504. [CrossRef]

176. Vedadghavami, A.; Zhang, C.; Bajpayee, A.G. Overcoming negatively charged tissue barriers: Drug delivery using cationic peptides and proteins. Nano Today 2020, 34, 100898. [CrossRef] [PubMed]

177. Campos, W.F.; Silva, E.C.; Oliveira, T.J.; Oliveira, J.M.; Tubino, M.; Pereira, C.; Vila, M.M.D.C.; Balcão, V.M. Transdermal permeation of bacteriophage particles by choline oleate: Potential for treatment of soft-tissue infections. Future Microbiol. 2020, 15, 881-896. [CrossRef] [PubMed] 